\title{
Thermal performance of a mine refuge chamber with human body heat sources under ventilation
}

\author{
Zujing Zhang ${ }^{\mathrm{a}, \mathrm{b}}$, Hongwei $\mathrm{Wu}^{\mathrm{c}}$, Kequan Wang ${ }^{\mathrm{b}}$, Rodney Day ${ }^{\mathrm{c}}$, Yanping Yuan ${ }^{\mathrm{a}^{*}}$ \\ ${ }^{\mathrm{a}}$ School of Mechanical Engineering, Southwest Jiaotong University, Chengdu, 610031, China \\ ${ }^{\mathrm{b} C h o n g q i n g}$ Research Institute of China Coal Technology \& Engineering Group, Chongqing, 400037, China \\ ${ }^{\mathrm{c}}$ School of Engineering and Technology, University of Hertfordshire, Hatfield, AL10 9AB, United Kingdom \\ *Corresponding author. Email: ypyuan@ home.swjtu.edu.cn
}

\begin{abstract}
This paper investigated the dynamic coupling heat transfer characteristics of rock and air in a Mine Refuge Chamber (MRC) under ventilation. In the current work, a comprehensive fiftyperson MRC model combining human-body heat sources and ventilation is established, the proposed model is validated against available experimental data with deviation less than $4 \%$. Furthermore, sensitivity analysis is performed to investigate the influence of several control parameters such as heating rate, ventilation and wall area in a MRC through using numerical simulation. Results indicated that: ( $\mathrm{i}$ ) the heat transfer process in a MRC will reach a stage of air temperature slow increase (ATSI) in less than $0.5 \mathrm{~h}$. The air temperature rises linearly with the square root of time during the ATSI stage; ( ii ) for a MRC built in a sandstone seam with an initial rock temperature of less than $27{ }^{\circ} \mathrm{C}$, the average air temperature will not exceed $35^{\circ} \mathrm{C}$ in $96 \mathrm{~h}$ when the ventilation volume rate is $0.3 \mathrm{~m}^{3} / \mathrm{min}$ per person; (iii) the rate of temperature rise in MRC is proportional to the rate of heat generation, but it is inversely proportional to the thermal conductivity, density and thermal capacity of the rock, as well as the ventilation volume rate and the wall area; (iv) an empirical correlation for the MRC average air temperature is developed while the supply air temperature equals to the initial rock temperature.
\end{abstract}

Keywords: Underground; Mine refuge chamber; Air temperature prediction; Ventilation; Heat transfer coefficient; Human body heat sources.

\begin{tabular}{|c|c|c|c|}
\hline \multicolumn{4}{|c|}{ Nomenclature } \\
\hline$a$ & Constant in $K$ expression & $V$ & Ventilation volume for MRC, $\mathrm{m}^{3} / \mathrm{h}$ \\
\hline$A_{\mathrm{w}}$ & Wall area of MRC, $\mathrm{m}^{2}$ & $x, y$ & Coordinate direction vector \\
\hline b & Constant in $K$ expression & Subscripts & \\
\hline$B$ & Temperature variable, ${ }^{\circ} \mathrm{C}$ & $\mathrm{a}$ & Air \\
\hline$c$ & Constant in $K$ expression & num & Numerical data \\
\hline$C_{\mathrm{a}}$ & Specific heat capacity of air, $\mathrm{J} /(\mathrm{kg} \cdot \mathrm{K})$ & $\exp$ & Experimental data \\
\hline$C_{\mathrm{p}}$ & Specific heat capacity of rock, $J /(\mathrm{kg} \cdot \mathrm{K})$ & Greek sym & bols \\
\hline$d$ & Constant in $K$ expression & $\alpha$ & Surface heat transfer coefficient, $\mathrm{W} /\left(\mathrm{m}^{2} \cdot \mathrm{K}\right)$ \\
\hline$i, j$ & Constant in $B$ expression & $\Theta$ & Difference \\
\hline$k$ & Constant in $B$ expression & $\rho$ & Density of rock, $\mathrm{kg} / \mathrm{m}^{3}$ \\
\hline$K$ & Rate for air temperature increasing, ${ }^{\circ} \mathrm{C} / \mathrm{s}^{0.5}$ & $\rho_{\mathrm{a}}$ & Density of air, $\mathrm{kg} / \mathrm{m}^{3}$ \\
\hline$l$ & Constant in $B$ expression & $\lambda$ & Thermal conductivity of rock, $\mathrm{W} /(\mathrm{m} \cdot \mathrm{K})$ \\
\hline$L$ & Temperature variable, ${ }^{\circ} \mathrm{C}$ & $\tau$ & Heat time, $\mathrm{h}$ \\
\hline$L_{\mathrm{c}}$ & Perimeter of cross-section tunnel, $\mathrm{m}$ & Acronyms & \\
\hline$m, n$ & Constant in $K$ expression & ATSI & Air temperature slow increase \\
\hline$p$ & Pressure, $\mathrm{Pa}$ & $\mathrm{CE}$ & Critical equilibrium \\
\hline$Q$ & Total heat generation rate in $\mathrm{MRC}, \mathrm{W}$ & MRC & Mine refuge chamber \\
\hline$r_{0}$ & equivalent radius of cross-section tunnel, $\mathrm{m}$ & MMRC & Movable mine rescue capsules \\
\hline$T$ & Temperature, ${ }^{\circ} \mathrm{C}$ & PCM & Phase change materials \\
\hline$T_{0}$ & Initial rock temperature, ${ }^{\circ} \mathrm{C}$ & & \\
\hline
\end{tabular}




\section{Introduction}

Global energy demand is growing with the improvement of human living standards, especially in developing countries with large populations, such as China ${ }^{[1]}$, India ${ }^{[2]}$ and South Africa ${ }^{[3]}$. In these countries, coal consumption accounts for a large proportion of energy consumption. Underground coal mining is renowned for being one of the most hazardous sectors in the world since coal accidents may occur at any time due to the complex environment. ${ }^{[4]}$ It is known that approximately $80 \%$ of the personnel trapped below ground in an accident died from carbon monoxide (CO) poisoning or hypoxia asphyxia during the escape process when coal mine explosion and fire accidents occurs. ${ }^{[5,6]}$ Mine refuge emergency system is considered as an effective measure to reduce casualties in coal mine accidents since it can provide a safe living place for miners to survive for over $96 \mathrm{~h} .{ }^{[7,8]}$ There are normally two main types of refuge facilities: Mine Refuge Chamber (MRC) and Movable Mine Rescue Capsules (MMRC). ${ }^{[9]}$ MRCs in an underground mine are constructed by excavating caverns from the strata on the sides of the escape route or equipping the cross headings in the mine with necessary refuge facilities and equipment. ${ }^{[10]}$ While MMRC is a steel-structure cabin which can be moved along with the underground mine working face. In China, MRC is the main refuge place in coal mine. However, high temperature and high concentration harmful gas issue accompanied with the accident becomes a problem in MRC due to human metabolism and harmful elements. ${ }^{[10,11]}$ As one of the basic conditions for safe survival, it is crucial to control the air temperature in the MRC. It should be noted that cooling a MRC is challenging since the electrical power supply is often interrupted during and after an accident as well as the risk of re-explosion still exists. This means conventional refrigeration methods cannot be applied. ${ }^{\text {[12] }}$ Therefore, it is imperative to develop no-electric-power or energy-saving methods to control the air temperature in MRC within a reasonable and survivable range.

Determination of the heat source and the allowable temperature range is the premise of cooling for a MRC. The heat in a MRC is mainly generated by people waiting for rescue. Nowadays, it is generally accepted that the heat generation rate of the human metabolic system is approximately $120 \mathrm{~W}$ per person and the $\mathrm{CO}_{2}$ generation rate is $0.32 \sim 0.37 \mathrm{~L} / \mathrm{min}$ per person when people are sitting quietly in MRC. ${ }^{[13,14]}$ In order to control the temperature in MRC at a lower cost as well as ensure personnel safety, we should be more concerned with the ultimate tolerance environment that people can withstand over $96 \mathrm{~h}$. At present, the recommended value of apparent temperature in MRC is below $35^{\circ} \mathrm{C} .{ }^{[15]}$ Apparent temperature takes into account four major environmental factors, i.e., wind, temperature, relative humidity and radiation from the sun or nearby surfaces, its calculation method can be found in ref. [16]. Du et al. ${ }^{[17]}$ pointed out that the conditions for the living environment should be controlled at a temperature less than $35^{\circ} \mathrm{C}$ and a relative humidity less than $80 \%$. $\mathrm{Li}$ et al. ${ }^{[18]}$ concluded that human responses could change significantly when exposed in the environment with a high temperature of $33{ }^{\circ} \mathrm{C}$ or relative humidity of $85 \%$.

In order to overcome the difficulty of electric-power shortages and save energy for MRC cooling, some low-electric-power or non-electric-power cooling technologies have been developed for MRC over recent years. Currently, five main cooling methods for MRC were reported, including explosion-proof air conditioning, ice storage cooling, $\mathrm{CO}_{2}$ phase-change cooling, PCM cooling and ventilation cooling. ${ }^{[19]}$ Among them, the explosion-proof air conditioning is mainly used in metallic and non-metallic mines but not in coal mine due to the refrigerator may not work when the gas explosion occurs. Jia et al. ${ }^{[20]}$ proposed a temperature control strategy by using an ice storage capsule within the MRC. They demonstrated that the strategy is effective in relation to the application of the refrigeration by an ice storage capsule within the MRC, through a 24-h manned experiment carried out in a closed cabin. $\mathrm{Xu}$ et al. ${ }^{[12]}$ proposed a non-electric-power cooling scheme that places the encapsulated ice plates directly in the MRC, their experiment showed that one plate had an average hourly cooling load of approximately $14.3 \mathrm{~W}$. Du et al. ${ }^{[14]}$ designed a multifunctional ice storage air conditioning system, the effective working time of this system being more than $96 \mathrm{~h}$ for an eight-person movable MRC. Wang et al. ${ }^{[21]}$ developed an ice thermal storage system as well as a proper control strategy of the system for a fifty-person MRC, the effective working time of the system was approximately $64.57 \mathrm{~h}$. Yang et al. ${ }^{[22]}$ designed an open $\mathrm{CO}_{2}$ phase-change cooling for MMRC. Their experimental results showed that the system can control the air temperature below $33{ }^{\circ} \mathrm{C}$ in a MMRC with a heat rate of $1200 \mathrm{~W}$. Gao et al. [19, 23 26] 
proposed a new coupled cooling method using the latent heat thermal energy storage combined with pre-cooling the envelope. According to their method, the MRC is pre-cooled via a forced-air system in normal times, during which time the surrounding rock and phase change materials (PCM) units placed within the MRC can absorb and store the cold energy. Ventilation could be the most economical measure for cooling a MRC, and it is also considered to be the most effective measure for supplying $\mathrm{O}_{2}$ and removing $\mathrm{CO}_{2}$ in a MRC. Ventilation cooling is mainly achieved by sending compressed air, generated by an air compressor on the ground, into the MRC through buried protected pipelines or ground drilling pipelines. There is no doubt that the effectiveness of ventilation cooling will be affected by factors such as the thermal properties of the rock, the ventilation volume, and the heating rate of heat sources in the MRC.

According to [27, 28], an underground profile with a buried depth more than $8 \mathrm{~m}$ is characterized as a deeply buried underground building in which the temperature remains almost constant throughout the year. MRCs can be considered as a deep buried underground building since a MRC is usually more than $200 \mathrm{~m}$ below the ground. In China, the minimum depth of a coal mine is $90 \mathrm{~m}$, which is far greater than $8 \mathrm{~m}$. Huang et al. ${ }^{[29]}$ pointed out that the heat transfer characteristics of the deeply buried underground buildings are mainly affected by surrounding rock parameters, heat sources, and ventilation conditions. Their test results showed that the heat transfer characteristics of rectangular or arched deep-buried underground buildings are similar to those of cylindrical buildings. The equivalent radius can be calculated as $r_{0}=L_{\mathrm{c}} / 2 \pi$. Xiao et al. ${ }^{[30]}$ proposed a Z-transfer method to calculate the unstable heat flow through the envelope of an underground cavern. Their results indicated that this method has a reliable computation accuracy with value difference less than $1 \%$ and high computation efficiency with computation time less than $1 \%$, compared with numerical method. Su et al. ${ }^{[31]}$ developed a numerical simulating model for a deeply buried airrock-tunnel heat exchanger to calculate the temperature and relative humidity of air in the tunnel as well as the rock temperature. Their results showed that the maximum error of the air temperature is $1.4{ }^{\circ} \mathrm{C}$ and the maximum error of the relative humidity is $10 \%$ according to the model. Sasmito et al. ${ }^{[32]}$ studied the thermal management strategies of a dead end in an underground mine ventilated through a pipe, their results showed that several control parameters such as the initial rock temperature, the ventilation temperature and the ventilation amount can have a significant effect on temperature control. Kajtar et al. ${ }^{[33,34]}$ developed a new dimensioning method for underground space to investigate the air and wall temperatures, as well as the heat flow through the wall. The method was in favor of the quick sizing of the required heating and cooling performance of underground spaces. However, the model can only be solved by a numerical way, which limits its application in engineering. Habibi et al. ${ }^{[35]}$ built a ventilation model to simulate the airflow and heat conditions for coal mine. Their results indicated that, for both flow and temperature, the model simulation predicted results agreed to within $9 \%$ accuracy of the actual measurements. Zhang et al. [36] designed a similar surrounding-rock laneway with ventilation to investigate the thermal exchange characteristics of air and surrounding rock in ventilated high geothermal roadways. Their results showed that the relationship between dimensionless temperature and dimensionless radius demonstrates an approximately exponential function. Li et al. ${ }^{[37]}$ analyzed the effect of air velocity and the relative roughness on the heat transfer of underground tunnels. Their results showed that both the temperature drop and the cooling efficiency increase gradually with the relative roughness increasing but decrease sharply with the air velocity increasing. Yantek et al. ${ }^{[38]}$ studied the effect of initial mine strata surface temperature and initial mine temperature on air temperature in a MMRC. It was found that the mine strata temperature increase has an important effect on the final temperature within the MMRC. Gao et al. ${ }^{[24 \sim 26]}$ systematically studied the temperature controlling characteristics of the PCM cooling plate and PCM cooling seat used in a fifty-person MRC, considering the coupled heat transfer characteristics between surrounding rock, air, and PCM. Most recently, Zhang et al. ${ }^{[1]}$ analyzed the thermal performance of a MRC and proposed a new analytical method to predict the air temperature in a MRC under natural convection. They concluded that the temperature in the MRC rises linearly with the square root of the heating time and the air temperature increasing trend becomes slow with the increase of the thermal conductivity, 
density and specific heat capacity of the rock.

There are few, if any, studies have been carried out on the dynamic coupled heat transfer of deeply buried underground close chamber under ventilation. Meanwhile, although some studies on the heat transfer of ventilated underground buildings have been reported, they are mainly applicable to open underground roadways or shallowly buried closed buildings. To determine whether ventilation can meet the temperature control requirement of a MRC, the characteristics of the coupled dynamic heat transfer process between the surrounding rock and air in MRC under ventilation by pipelines will be mainly investigated in the current work. The purpose of the study is to demonstrate the trend of air temperature increases in MRC with the heating time, and to reveal the influences of the several control factors such as thermal properties of the surrounding rock, heat generation rate of heat sources, ventilation parameters and wall area on the heat transfer between the air and rock. Thereafter, with the assistance of a fifty-person MRC as an case study, a comprehensive fiftyperson MRC geometric model under ventilation is newly established. The heat transfer characteristics of the MRC are analyzed by ANSYS Fluent ${ }^{[39]}$. The control factors such as the thermal properties of the rock, heat source, and parameters of the air flow affecting the temperature rises will be investigated in detail.

\section{Computational details}

\subsection{Computational model and mesh}

In the current work, a computational model of a fifty-person MRC was developed. For the purpose of validation, the internal size of the MRC is $20 \mathrm{~m}$ in length, $3 \mathrm{~m}$ in height, and $4 \mathrm{~m}$ in width was selected, which is consist with the available experimental work [11]. It is known that the thickness of the heat-regulating circle of the surrounding rock for MRC within $96 \mathrm{~h}$ is approximately $2 \mathrm{~m} .{ }^{[19]}$ In the current MRC model, the thickness of the wall is $2.5 \mathrm{~m}$. There are 5 air inlets with a diameter of $0.075 \mathrm{~m}$ on each side of the two long sides. The inlet is $1.8 \mathrm{~m}$ above the ground, and the distance between two adjacent inlets is $3.5 \mathrm{~m}$. At both ends of the MRC, there is an air outlet with a diameter of $0.3 \mathrm{~m}$ on each side. The outlet is $2.2 \mathrm{~m}$ above the ground. 50 human body models with a surface area of $2 \mathrm{~m}^{2}$ are divided into 4 rows in the room, as shown in Fig. 1.

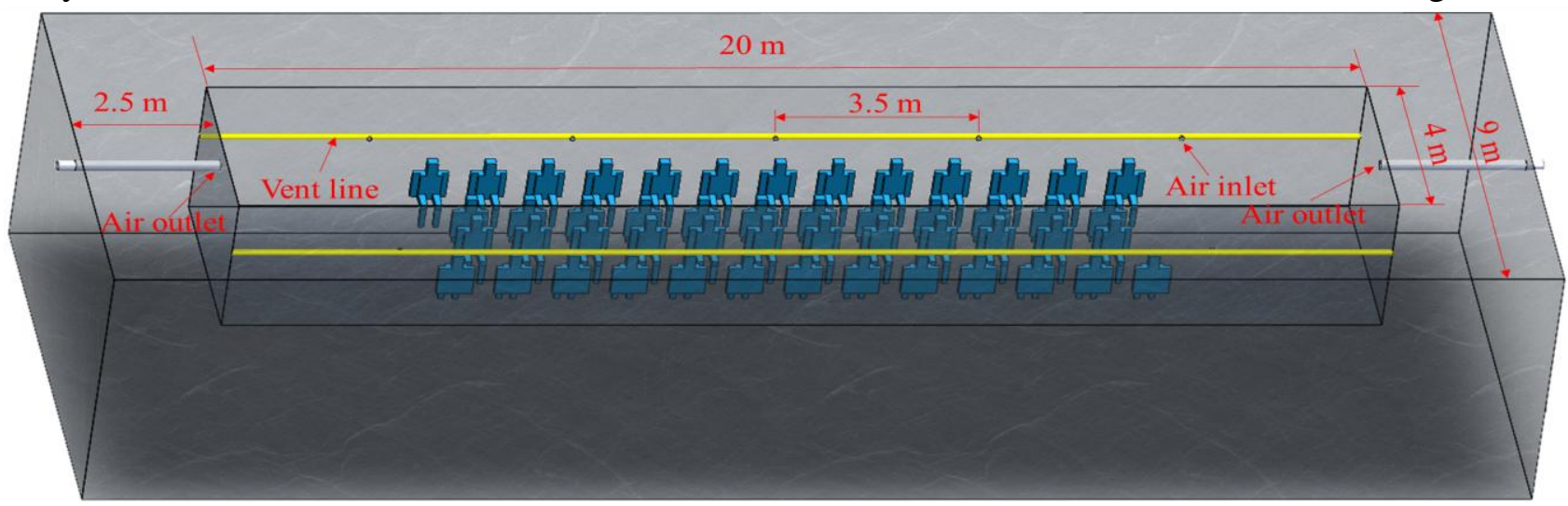

Fig. 1. Geometric model of a fifty-person MRC.

The computational grids are generated by ANSYS ICEM ${ }^{[40]}$. Considering the complexity of the model, unstructured grid is adopted. In order to ensure that the numerical results are independent of the grid, a grid independence study is performed by using six different meshes with $9.7 \times 10^{5}, 15.6 \times 10^{5}$, $21.3 \times 10^{5}, 2.75 \times 10^{6}, 3.15 \times 10^{6}$ and $4.14 \times 10^{6}$ cells, respectively. It can be seen from Fig. 2 that the numerical results are not strongly affected when the number of cells over $21.3 \times 10^{5}$.

For the sake of computing resource economics, the mesh with $2.75 \times 10^{6}$ cells is selected. The maximum grid size of the inner walls, the external walls, human-body surfaces, the inlet surfaces and the outlet are $0.1 \mathrm{~m}, 0.5 \mathrm{~m}, 0.06 \mathrm{~m}, 0.002 \mathrm{~m}$ and $0.005 \mathrm{~m}$, respectively. The maximum grid size of the fluid zone and the solid zone is $0.2 \mathrm{~m}$ and $0.5 \mathrm{~m}$, respectively. Fig. 3 shows the cross section of the model mesh. 


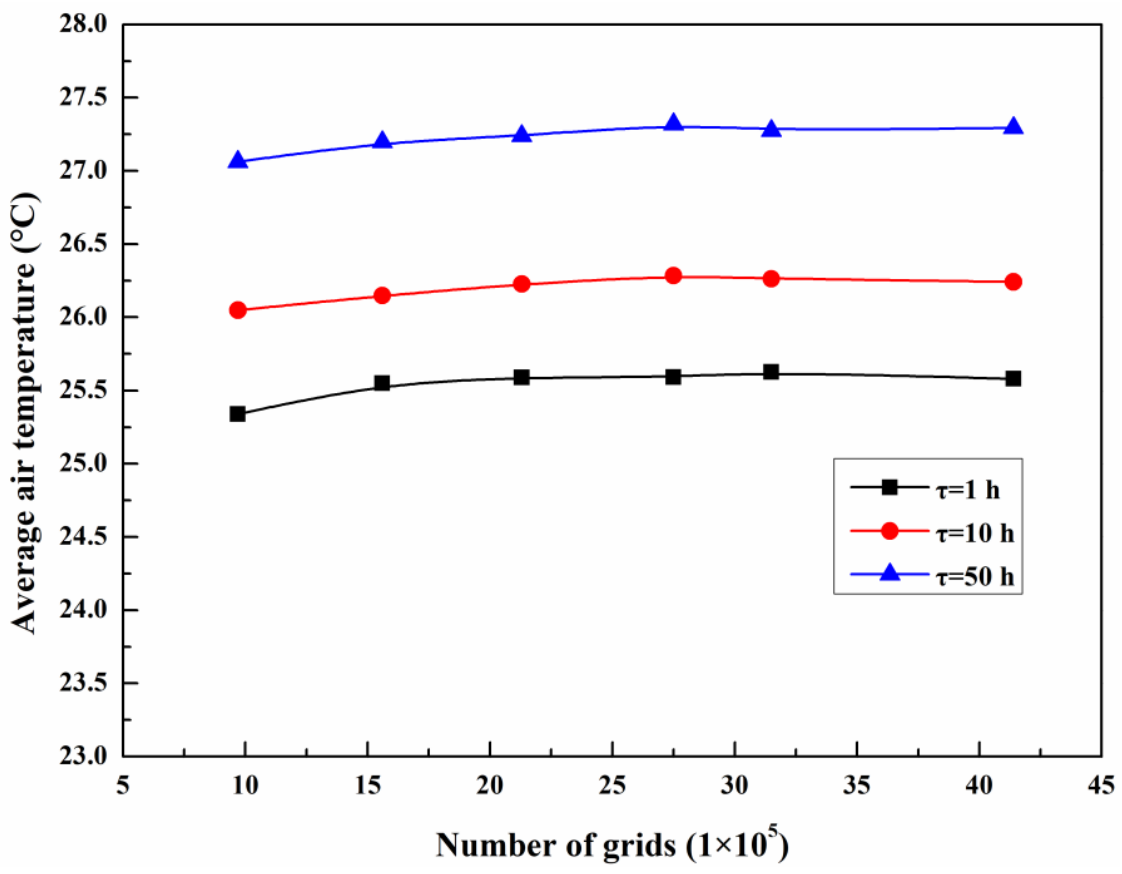

Fig. 2. Comparisons of numerical results with six different grids.
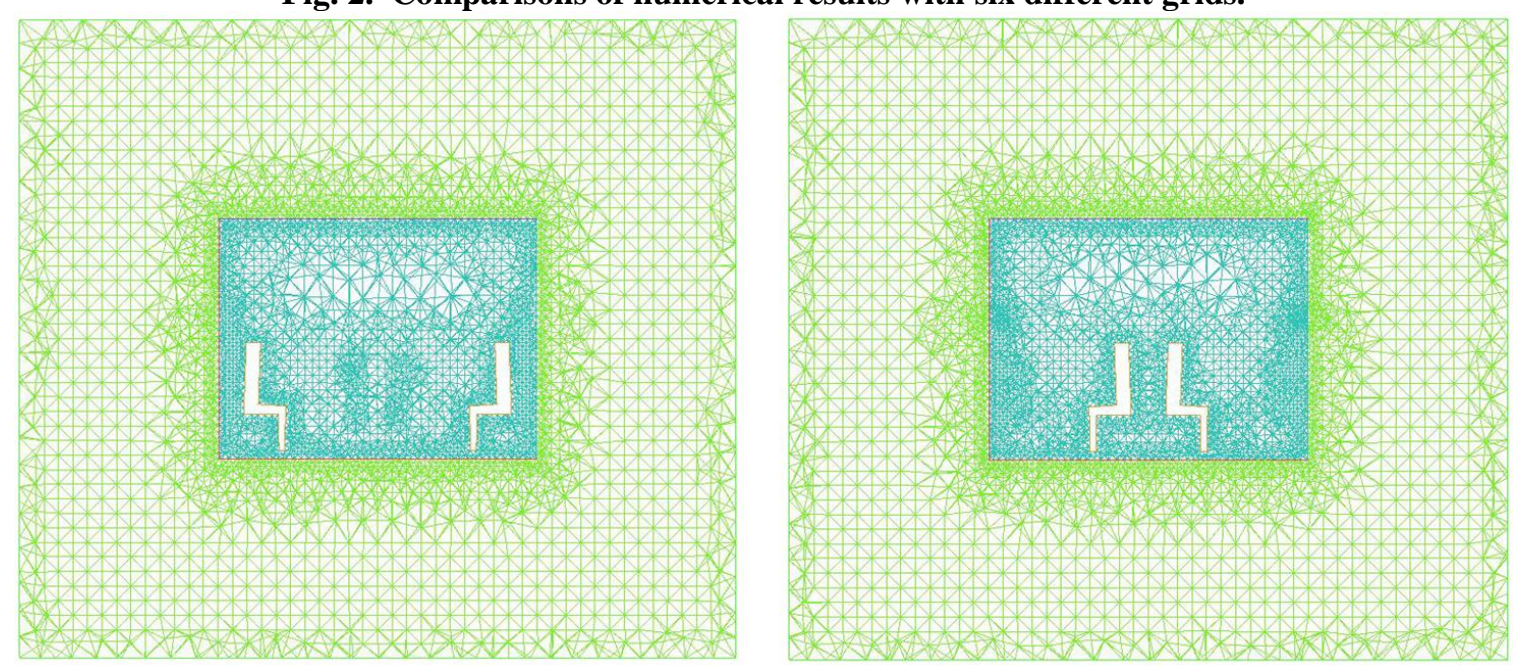

Fig. 3. Cross section of the model mesh

\subsection{Turbulence model}

In the current work, the diameter of the air inlets is $0.075 \mathrm{~m}$, the average velocity of the air inlets are $2,3,4,6,8$ and $10 \mathrm{~m} / \mathrm{s}$, and the kinematic viscosity of the air ranges from $1.55 \times 10^{-5} \mathrm{~m}^{2} / \mathrm{s}$ to $1.65 \times 10^{-5} \mathrm{~m}^{2} / \mathrm{s}$, and the $R e$ value of air inlets can vary from 9091 to 48387 . Thus, the air flow in the MRC can be considered as turbulent.

A realizable $k-\varepsilon$ turbulent model will be used since it is known to have a good performance with indoor airflows, temperature and pressure in closed structures. ${ }^{[41-45]}$ In the turbulence model, the enhanced wall treatment with pressure gradient effects and thermal effects, and the full buoyancy effect under gravity have been taken into account, but the viscous heating is ignored since the air flows in the living room at a low speed and there is almost no mechanical energy be converted into heat.

\subsection{Initial and boundary conditions}

It is recognized that a conventional MRC is usually built in sandstone rock to ensure the strength of the structure. The thermal conductivity, specific heat capacity and density of sandstone are 2 $\mathrm{W} /(\mathrm{m} \cdot \mathrm{K}), 920 \mathrm{~J} /(\mathrm{kg} \cdot \mathrm{K})$ and $2400 \mathrm{~kg} / \mathrm{m}^{3}$, respectively. ${ }^{[11,23 \sim 25]}$ In the current work, the initial rock 
temperature and the air temperature in the MRC are $25{ }^{\circ} \mathrm{C}$. The $\mathrm{CO}_{2}$ concentration in MRC could be controlled below $1 \%$ when the ventilation volume rate was $0.1 \mathrm{~m}^{3} / \mathrm{min}$ per person ${ }^{[46]}$. Therefore, the heat generated by the MRC's carbon dioxide scrubbing system will not be considered since the $\mathrm{CO}_{2}$ is removed from the MRC by the airflow when ventilation is supplied for MRC. It is recognized that the heat flux of a human body surface is $60 \mathrm{~W} / \mathrm{m}^{2}$ since the calorie generated by an adult man sitting in a room is approximately $120 \mathrm{~W}^{[11,14,38,47]}$. The velocity at each of the ten air inlets is $6 \mathrm{~m} / \mathrm{s}$ since the fresh air supply rate in an MRC is specified to be $0.3 \mathrm{~m}^{3} / \mathrm{min}$ per person ${ }^{[48]}$. Turbulence intensity, turbulence length scale, turbulence Kinetic energy, and turbulence dissipation energy for the inlets is $5 \%, 1 \mathrm{~m}, 1 \mathrm{~m}^{2} / \mathrm{s}^{2}, 1 \mathrm{~m}^{2} / \mathrm{s}^{3}$, respectively. The temperature of the air inlet is equal to the initial rock temperature since the air supply pipeline needs long-distance buried protection and there is heat exchange between the air, pipeline wall, and surrounding rock.

\subsection{Other setup}

Boussinesq assumption is used for air operating density to deal with buoyancy term introduced by temperature difference. At standard pressure and $25^{\circ} \mathrm{C}$, the initial air density is $1.225 \mathrm{~kg} / \mathrm{m}^{3}$. Pressure-implicit with splitting of operators (PISO) is applied. The pressure is discretized by using the standard schemes. The energy, momentum, turbulent kinetic energy, turbulent dissipation, and the transient formulation are discretized by using the second-order upwind schemes. The convergence absolute criteria for energy is $10^{-6}$, for other items is $10^{-3}$. The calculation is convergent when the time step is within $30 \mathrm{~s}$, and it is shown that the numerical results are independent of the time step. In the current work, the time step is $10 \mathrm{~s}$.

\subsection{Model validation}

To verify the applicability of the current numerical model, the numerical results are compared with previously published experimental data in ref. [11]. The experiment was carried out in a fiftypeople MRC laboratory without air supply for the MRC. The wall of the MRC laboratory is made of concrete with the density of $1600 \mathrm{~kg} / \mathrm{m}^{3}$, the specific heat capacity of $840 \mathrm{~J} /(\mathrm{kg} \cdot \mathrm{K})$ and the thermal conductivity of $0.81 \mathrm{~W} /(\mathrm{m} \cdot \mathrm{K})$. In the experiment, 40 heat lamps with $150 \mathrm{~W}$ representing the heat production of 50 persons. The initial air temperature in the MRC is $25{ }^{\circ} \mathrm{C}$ and the initial wall temperature is $22.3{ }^{\circ} \mathrm{C}$. It was demonstrated that the experimental result could not be affected by the external environment within $10.3 \mathrm{~h}$.

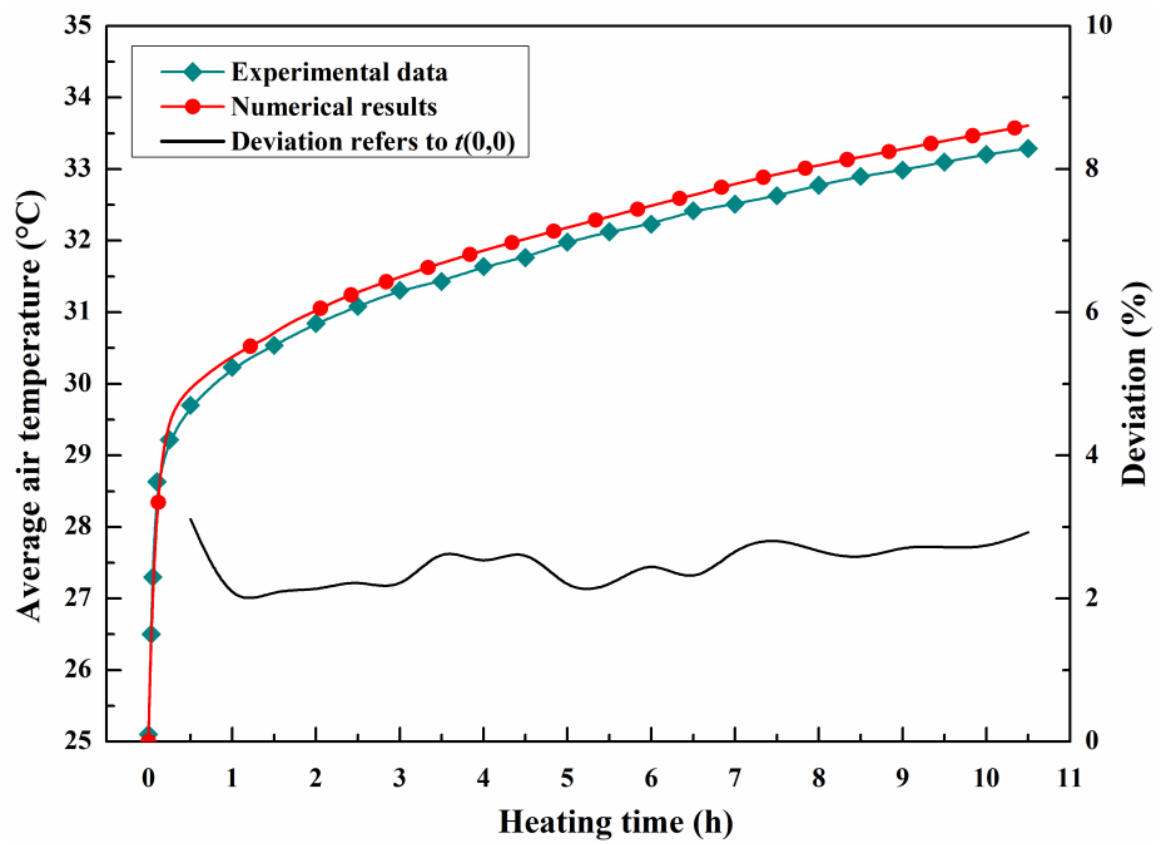

Fig. 4. Comparison of the experimental and numerical results. 
Fig. 4 shows the comparison between the present numerical results and the experimental data. The deviation between the numerical results and the experimental data is calculated based on the initial rock temperature $\left(22.3{ }^{\circ} \mathrm{C}\right)$, namely, $\Theta=\left(T_{\text {num }}-T_{\exp }\right) /\left(T_{\exp }-T_{0}\right)$. It can be found that the predicted air temperature agrees well with the experimental data. From $0.5 \sim 10.5 \mathrm{~h}$, the temperature difference between the predicted result and the experimental data is less than $0.5{ }^{\circ} \mathrm{C}$. Within $0.5 \sim 1 \mathrm{~h}$, the deviation decreases with time from $3.3 \%$ to $2 \%$. Within $1 \sim 10.5 \mathrm{~h}$, the deviation varies within $2 \% \sim 2.9 \%$. It can be confirmed that the current numerical model is suitable for application since the predicted result is in good agreement with the experimental data with the deviation less than $5 \%$.

\section{Results and discussion}

\subsection{Heat transfer characteristics of the conventional MRC}

\subsubsection{Air temperature rise}

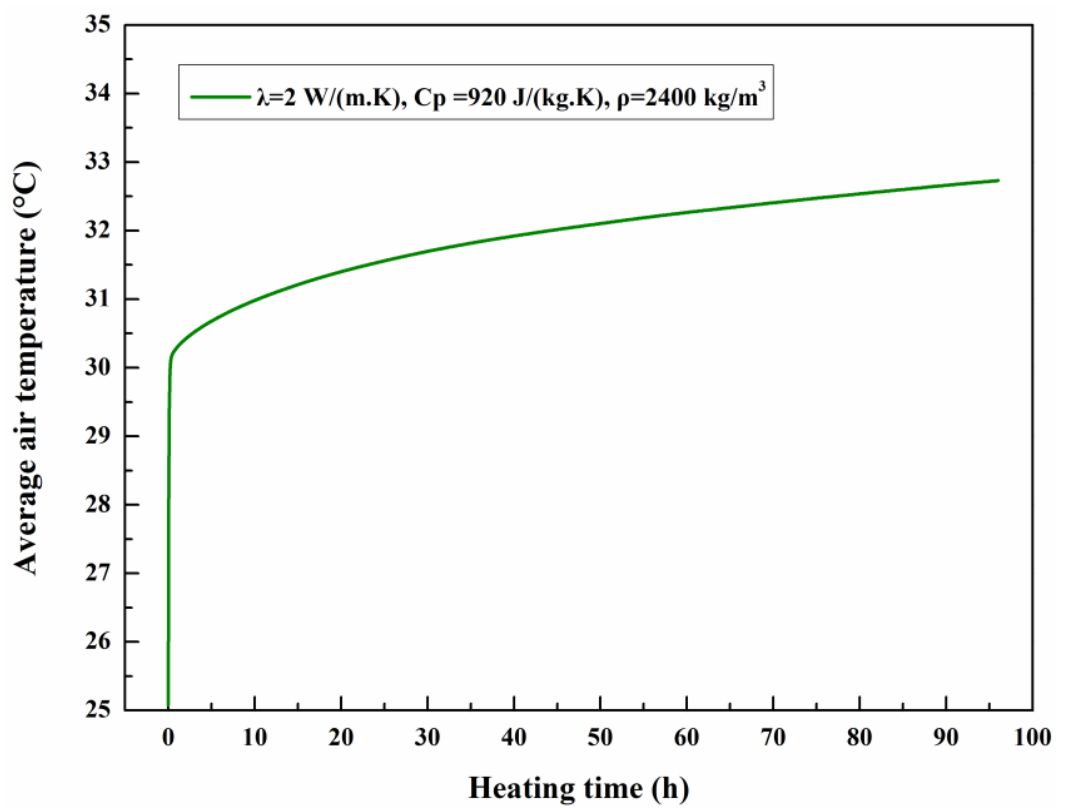

Fig. 5. Average air temperature varies with $\tau$.

Fig. 5 shows the average air temperature in the MRC varies with time within 96 h. From Fig. 5, it can be seen that, during the initial period of heating, the air temperature rises quickly from $25{ }^{\circ} \mathrm{C}$ to about $30.2{ }^{\circ} \mathrm{C}$ in less than $0.5 \mathrm{~h}$. After that, the heat transfer process between the wall and air in MRC will present a relatively dynamic balance, and the air temperature rise rate will decrease with time. For convenience, the air temperature at the time of the dynamic balance critical point is defined as the Critical Equilibrium (CE) temperature, and the heat transfer process in the relative dynamic balanced state is defined as a stage of Air Temperature Slow Increase (ATSI). During the ATSI stage, the heat generated by human metabolic in the MRC is mainly absorbed by the rock through the heat transfer between air and walls, and the remaining heat is taken out from the MRC by the airflow through the air outlets. It can be found that the value of the air temperature rise is less than $3{ }^{\circ} \mathrm{C}$ from 0.5 to $96 \mathrm{~h}$. At $\tau=96 \mathrm{~h}$, the average air temperature is approximately $32.7{ }^{\circ} \mathrm{C}$. It can be deduced that when the initial temperature of the rock is $27{ }^{\circ} \mathrm{C}$, the air temperature in the MRC at $96 \mathrm{~h}$ is less than $35^{\circ} \mathrm{C}$. Taking $35^{\circ} \mathrm{C}$ as the upper limit air temperature in MRC, it means that for a MRC built in sandstone rock with the initial rock temperature less than $27^{\circ} \mathrm{C}$, the average air temperature will not exceed $35^{\circ} \mathrm{C}$ within $96 \mathrm{~h}$ when the ventilation rate is $0.3 \mathrm{~m}^{3} / \mathrm{min}$ per person and people are sitting or lying quietly in the MRC, and it could not need to take another cooling measure for temperature control. 


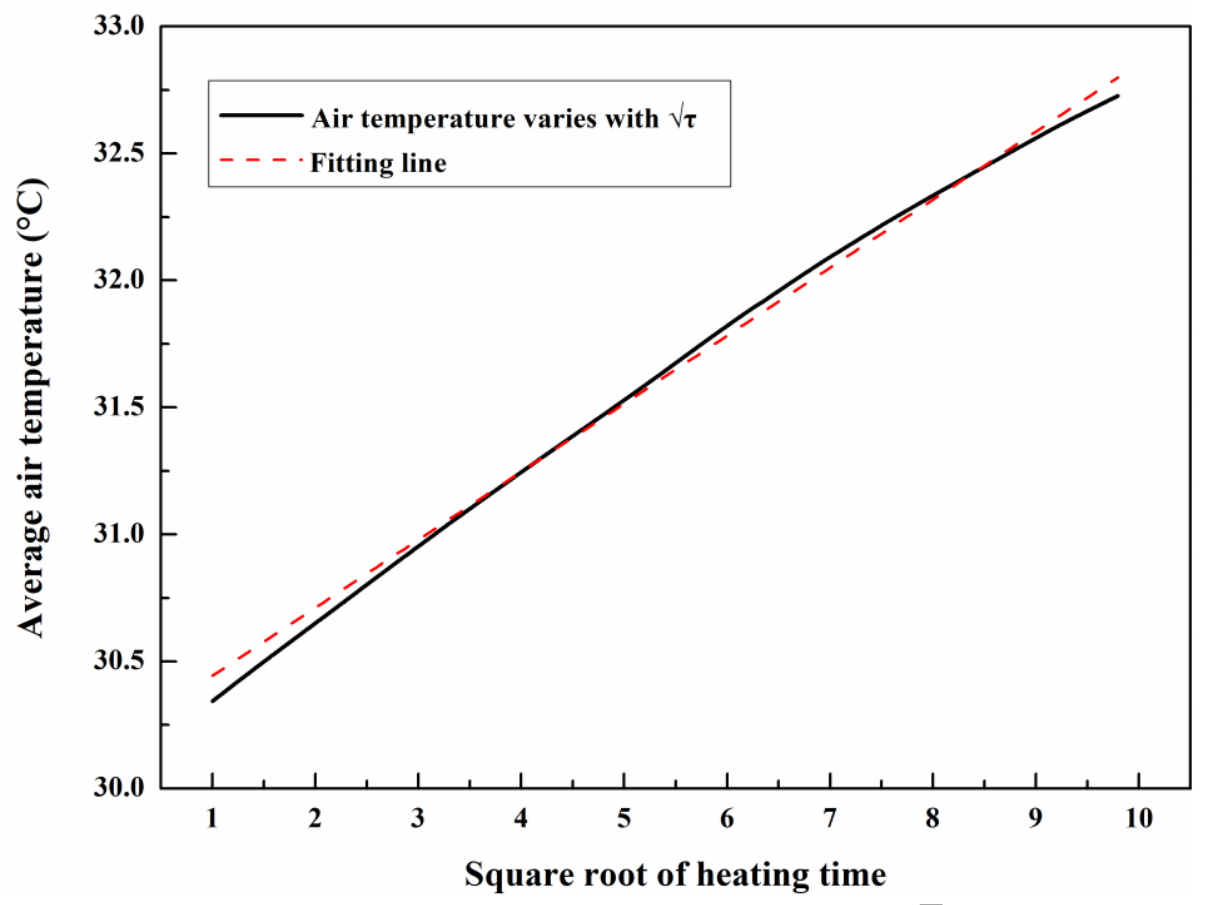

Fig. 6. Average air temperature varies with $\sqrt{\tau}$.

Fig. 6 illustrates the variation of the average air temperature in the MRC varies with the square root of time from 1 to $96 \mathrm{~h}$. It can be found from Fig. 6 that the air temperature increases linearly with the square root of the time. At $\tau=1 \mathrm{~h}$, the difference between the predicted data and the linear value has a maximum value of $0.2^{\circ} \mathrm{C}$. When $1 \leq \tau \leq 3.5 \mathrm{~h}$, the difference gradually decreases with time. This may be caused by the surface heat transfer coefficient tends to be stable with air temperature rising slowly. According to the numerical data, the linear fitting formula can be expressed as $y=0.2625 x+30.203, R^{2}=0.9956$. Therefore, during the 96-hour service time, the air temperature in MRC can be expressed as

$$
T_{\text {air }}(\tau)=K \sqrt{\tau}+L=K \sqrt{\tau}+B+T_{0}
$$

It can be found that the calculation method of $K$ and $B$ needs to be determined firstly for the air temperature prediction in MRC. Both $K$ and $B$ may be related to thermal properties of the surrounding rock, ventilation volume, heat generation rate of heat sources and wall area of the MRC. Among these main control factors, the thermal properties of the surrounding rock are independent of the other factors. Therefore, $K$ and $B$ can be defined as

$$
\begin{aligned}
& K=f\left(V, Q, A_{\mathrm{w}}, \alpha, \lambda, \rho, C_{\mathrm{P}}\right)=f\left(V, Q, A_{\mathrm{w}}, \alpha\right) \cdot f\left(\lambda, \rho, C_{\mathrm{P}}\right) \\
& B=F\left(V, Q, A_{\mathrm{w}}, \alpha, \lambda, \rho, C_{\mathrm{P}}\right)=F\left(V, Q, A_{\mathrm{w}}, \alpha\right) \cdot F\left(\lambda, \rho, C_{\mathrm{P}}\right)
\end{aligned}
$$

In the following sensitivity analysis, changes in $K$ and $B$ caused by different factors will be mainly discussed to obtain the corresponding calculation method.

\subsubsection{Temperature distribution in the MRC and the surrounding rock}

Fig. 7 presents the air temperature distribution in the MRC at several different time, i.e. $0.5 \mathrm{~h}, 1 \mathrm{~h}$, $10 \mathrm{~h}, 40 \mathrm{~h}, 70 \mathrm{~h}, 96 \mathrm{~h}$. It can be found from Fig. 7 that the air temperature distribution at $0.5 \mathrm{~h}$ is not uniform, the temperature ranges from $27{ }^{\circ} \mathrm{C}$ to $30.5^{\circ} \mathrm{C}$, and the air temperature in the area affected by the jet flow is relatively low. As time increases, the temperature distribution in the MRC becomes more and more uniform. At $1 \mathrm{~h}$, the air temperature in the MRC ranges from $28.5{ }^{\circ} \mathrm{C}$ to $31{ }^{\circ} \mathrm{C}$. At $10 \mathrm{~h}$, the air temperature in the overall $\mathrm{MRC}$ is $29.5 \sim 31.5^{\circ} \mathrm{C}$ with a difference less than $2{ }^{\circ} \mathrm{C}$. It can be found that at $40 \mathrm{~h}$, the air temperature is $31 \sim 32.5^{\circ} \mathrm{C}$, and the rock temperature in the range of $0.5 \mathrm{~m}$ has significantly changed. The temperature in the MRC at $70 \mathrm{~h}$ is $31.5 \sim 33{ }^{\circ} \mathrm{C}$. At $96 \mathrm{~h}$, the air temperature in the overall MRC is below $34{ }^{\circ} \mathrm{C}$ with a difference less than $1.5^{\circ} \mathrm{C}$. 


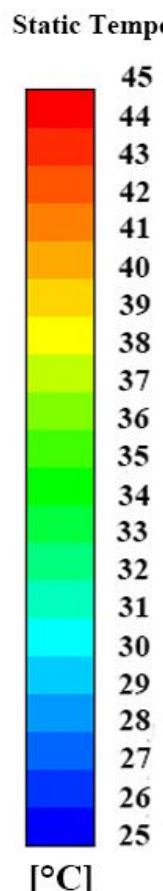

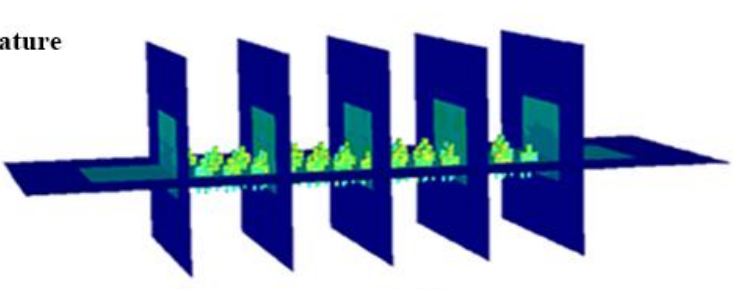
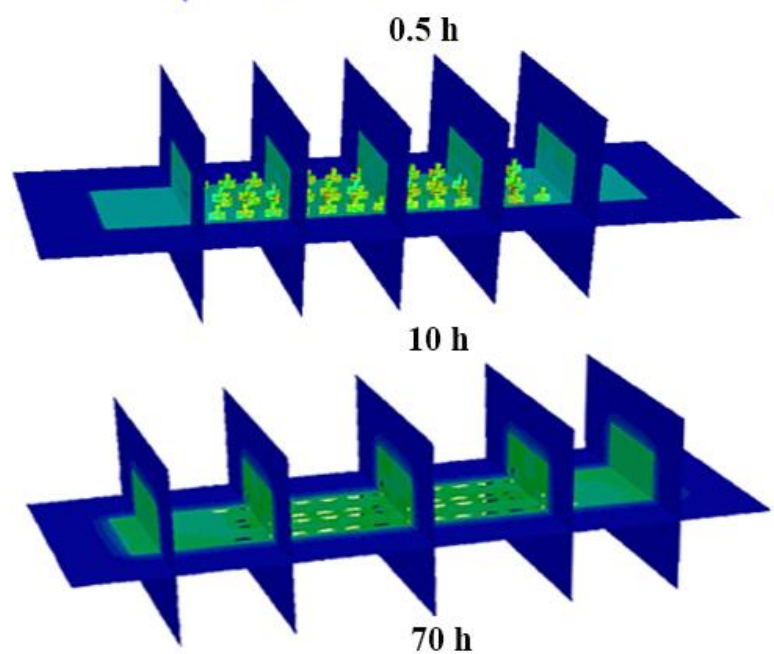

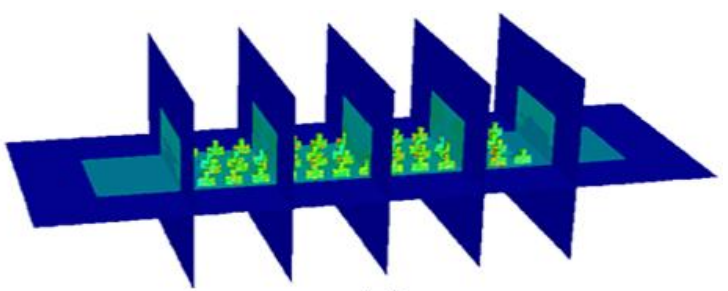

$1 \mathrm{~h}$

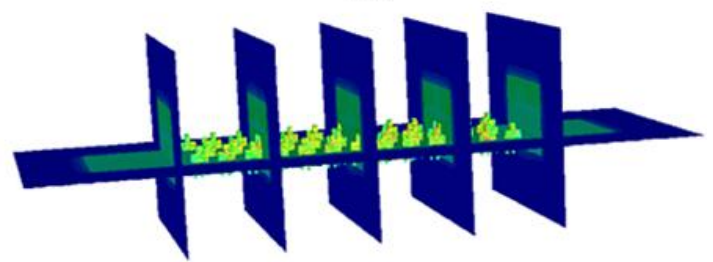

$40 \mathrm{~h}$

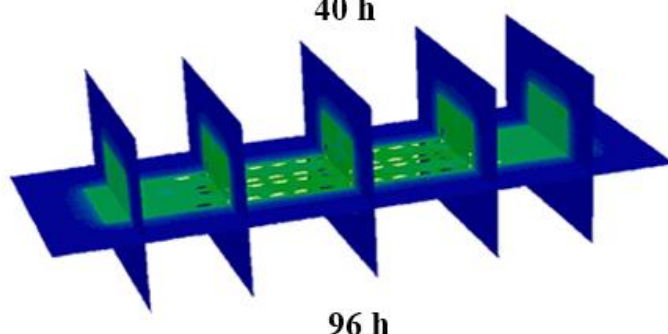

Fig. 7. Air temperature distribution in the MRC at different time.

Static Temperature

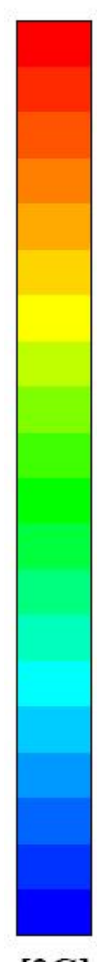

$\left[{ }^{\circ} \mathrm{C}\right]$
27.0

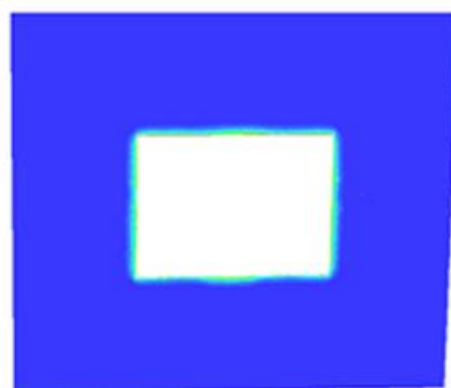

2 h

26.4

26.2

26.0

25.5

25.0

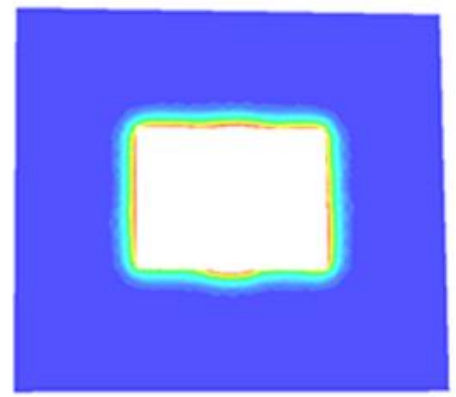

$10 \mathrm{~h}$

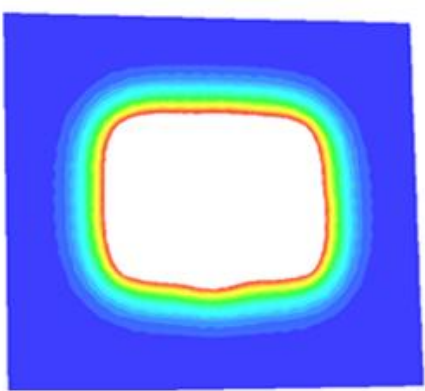

$70 \mathrm{~h}$

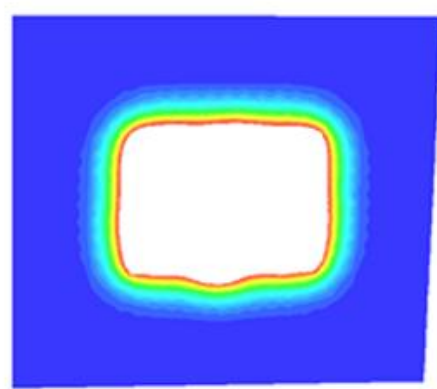

$40 \mathrm{~h}$

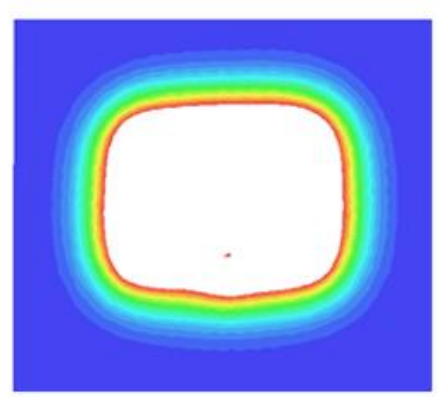

$96 \mathrm{~h}$

Fig. 8. Temperature variation of the surrounding rock at different time.

Fig. 8 demonstrates the temperature variation of the rock at several different time, i.e. $2 \mathrm{~h}, 10 \mathrm{~h}$, $40 \mathrm{~h}, 50 \mathrm{~h}, 70 \mathrm{~h}, 96 \mathrm{~h}$. The rectangles look deformed since there is a slight tilt in saving the figure to obtain a high contrast temperature contour. It can be seen from Fig. 8 that at $2 \mathrm{~h}$, the wall temperature is approximately $26.5{ }^{\circ} \mathrm{C}$, and the affected zone of the surrounding rock is mainly concentrated near the wall. As time increases, the temperature-effected area by the heat transfer becomes larger. At $10 \mathrm{~h}$, the wall temperature exceeds $27^{\circ} \mathrm{C}$, and the affected area of the rock has 
significantly increased compared with that at $2 \mathrm{~h}$. It can be found from the temperature at $40 \mathrm{~h}, 50 \mathrm{~h}$, $70 \mathrm{~h}$, and $96 \mathrm{~h}$ that the temperature-effected zone of the surrounding rock expands outward in a ring shape over time. The radius of the affected zone at $96 \mathrm{~h}$ is $2.2 \mathrm{~m}$, which is less than $2.5 \mathrm{~m}$ and close to the reference value of $2 \mathrm{~m}$ given in ref. [19].

\subsubsection{Wall heat transfer coefficient}

Fig. 9 demonstrates the variation of the surface heat transfer coefficient with time in different directions of the walls. It can be found that there are certain differences in the surface heat transfer coefficient in different directions. The surface heat transfer coefficient at the vertical wall is the largest with the value of $5.3 \sim 5.7 \mathrm{~W} /\left(\mathrm{m}^{2} \cdot \mathrm{K}\right)$, the lowest one is at the bottom wall with the value of $3.9 \sim 4.1 \mathrm{~W} /\left(\mathrm{m}^{2} \cdot \mathrm{K}\right)$, and the value at the top wall is $4.6 \sim 4.8 \mathrm{~W} /\left(\mathrm{m}^{2} \cdot \mathrm{K}\right)$. Within $5 \sim 30 \mathrm{~h}$, the vertical heat transfer coefficient has a slight decreasing, which may be caused by the air temperature change. From $5 \mathrm{~h}$ to $96 \mathrm{~h}$, the average heat transfer coefficient is $4.9 \sim 5.0 \mathrm{~W} /\left(\mathrm{m}^{2} \cdot \mathrm{K}\right)$

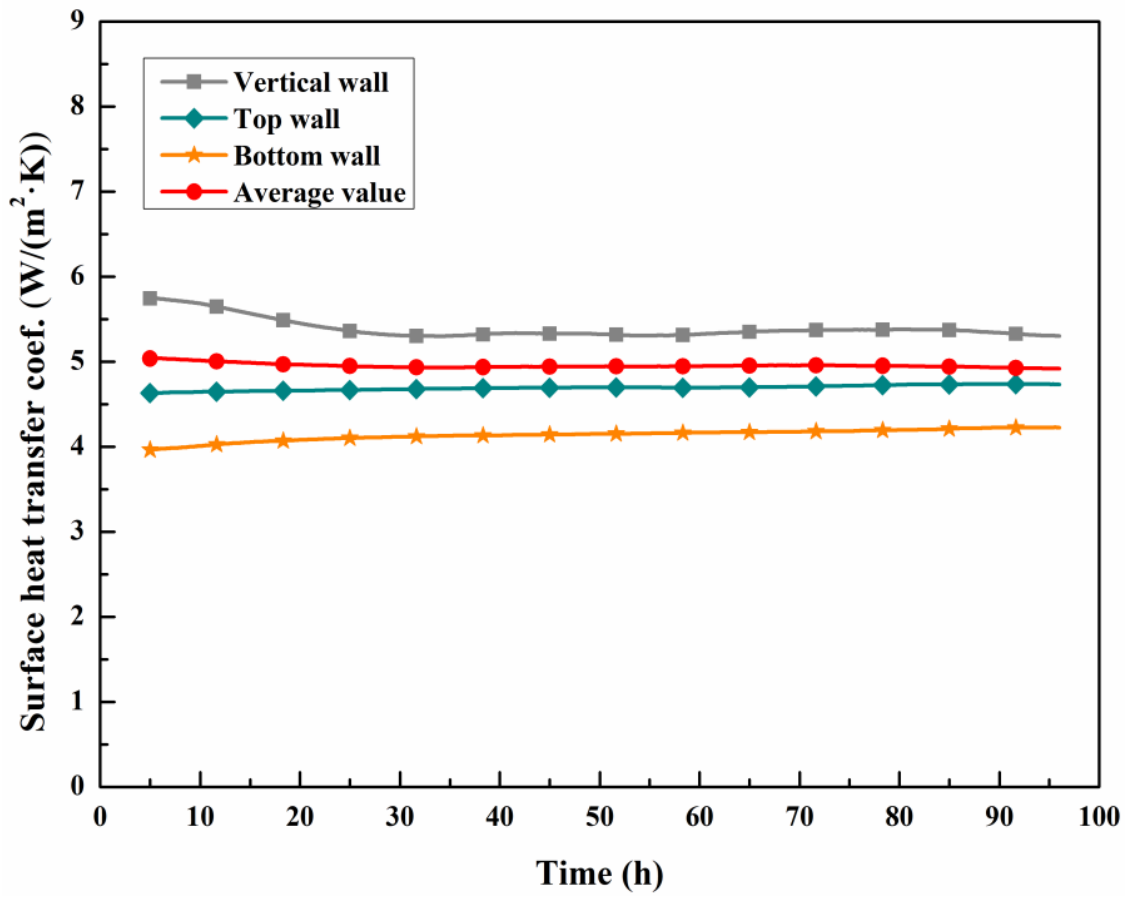

\subsection{Sensitivity analysis}

The initial rock temperature will not be considered since it is independent of the trend of air temperature increase in MRC, according to ref. [29]. However, there is no doubt that the dynamic coupled heat transfer characteristics of the rock and air in MRC under ventilation will be affected by the thermal properties of the rock, the heat rate of heat sources in MRC, the volume and temperature of ventilation as well as the wall area of MRC. As is always the case, the temperature of the fresh air supplied by pipeline will be equal to the initial rock temperature due to the long $(>1$ $\mathrm{km})$ air-supply pipeline and the heat exchange between the pipeline and the external environment (Air in tunnel and Surrounding Rock in direct contact with the pipeline). Therefore, the temperature of ventilation will not be considered in the current work. In order to investigate the influences of these control factors, i.e. the thermal conductivity and specific heat capacity as well as density of the rock, heat rate of heat sources in MRC, ventilation volume rate for MRC and wall area of the MRC, a series of numerical cases are conducted for each factor. For the purpose of comparison, only one parameter value will be changed in each numerical case whereas the other parameters are kept the same with the above conventional MRC case (namely, $T_{0}=25{ }^{\circ} \mathrm{C}, T_{\mathrm{a}}(0)=25{ }^{\circ} \mathrm{C}, \lambda=2$ $\left.\mathrm{W} /(\mathrm{m} \cdot \mathrm{K}), C_{\mathrm{P}}=920 \mathrm{~J} /(\mathrm{kg} \cdot \mathrm{K}), \rho=2400 \mathrm{~kg} / \mathrm{m}^{3}, Q=6000, V=900 \mathrm{~m}^{3} / \mathrm{h}, T_{\text {in }}=25{ }^{\circ} \mathrm{C}, A_{\mathrm{w}}=304 \mathrm{~m}^{2}\right)$. The related parameters are shown in Table 1. 
Table 1. Variable parameter value for sensitivity analysis cases.

\begin{tabular}{|c|c|c|c|c|}
\hline Type of factors & Variable Name & symbol & Unit & Variable value \\
\hline \multirow{2}{*}{ Initial value } & Initial rock temperature & $T_{0}$ & ${ }^{\circ} \mathrm{C}$ & 25 \\
\hline & Initial air temperature in MRC & $T_{\mathrm{a}}(0)$ & ${ }^{\circ} \mathrm{C}$ & 25 \\
\hline \multirow{3}{*}{$\begin{array}{l}\text { Material } \\
\text { properties }\end{array}$} & Thermal conductivity of rock & $\lambda$ & $\mathrm{W} /(\mathrm{m} \cdot \mathrm{K})$ & $1,1.5,2,2.5,3$ \\
\hline & Specific heat capacity of rock & $C_{\mathrm{p}}$ & $\mathrm{J} /(\mathrm{kg} \cdot \mathrm{K})$ & $800,860,920,1000,1100$ \\
\hline & Density of rock & $\rho$ & $\mathrm{kg} / \mathrm{m}^{3}$ & $1500,2000,2400,3000,3500$ \\
\hline \multirow{2}{*}{$\begin{array}{l}\text { Thermal } \\
\text { boundary }\end{array}$} & Heat flux of human-body surfaces & $q_{\mathrm{h}}$ & $\mathrm{W} / \mathrm{m}^{2}$ & $50,60,70,80,90$ \\
\hline & Heat rate in MRC (equivalent) & $Q$ & $\mathrm{~W}$ & $5000,6000,7000,8000,9000$ \\
\hline \multirow{3}{*}{ Inlet boundary } & Velocity & $v$ & $\mathrm{~m} / \mathrm{s}$ & $2,3,4,6,8,10$ \\
\hline & Ventilation volume rate for MRC (equivalent) & $V$ & $\mathrm{~m}^{3} / \mathrm{h}$ & $300,450,600,900,1200,1500$ \\
\hline & Air temperature & $T_{\text {in }}$ & ${ }^{\circ} \mathrm{C}$ & 25 \\
\hline \multirow{2}{*}{$\begin{array}{c}\text { Wall area of } \\
\text { MRC }\end{array}$} & Inner length of MRC & $L_{\text {in }}$ & $\mathrm{m}$ & $14,16,18,20$ \\
\hline & Wall area of MRC (equivalent) & $A_{\mathrm{w}}$ & $\mathrm{m}^{2}$ & $220,248,276,304$ \\
\hline
\end{tabular}

It needs to be stressed here that, in order to analyze the effect of wall area of MRC, the geometric structure of the MRC model will be modified from $20 \mathrm{~m}$ to $14 \mathrm{~m}, 16 \mathrm{~m}$ and $18 \mathrm{~m}$ in length, respectively. In the due course, the modified models need to be meshed again. It is known that the grid quality will affect the numerical analysis in terms of the numerical calculation results or the calculation speed. In order to make the calculated results not to be affected by the grid quality, the meshing parameters of the modified models are consistent with the previous numerical model.

\subsubsection{Effect of thermal properties of surrounding rock}

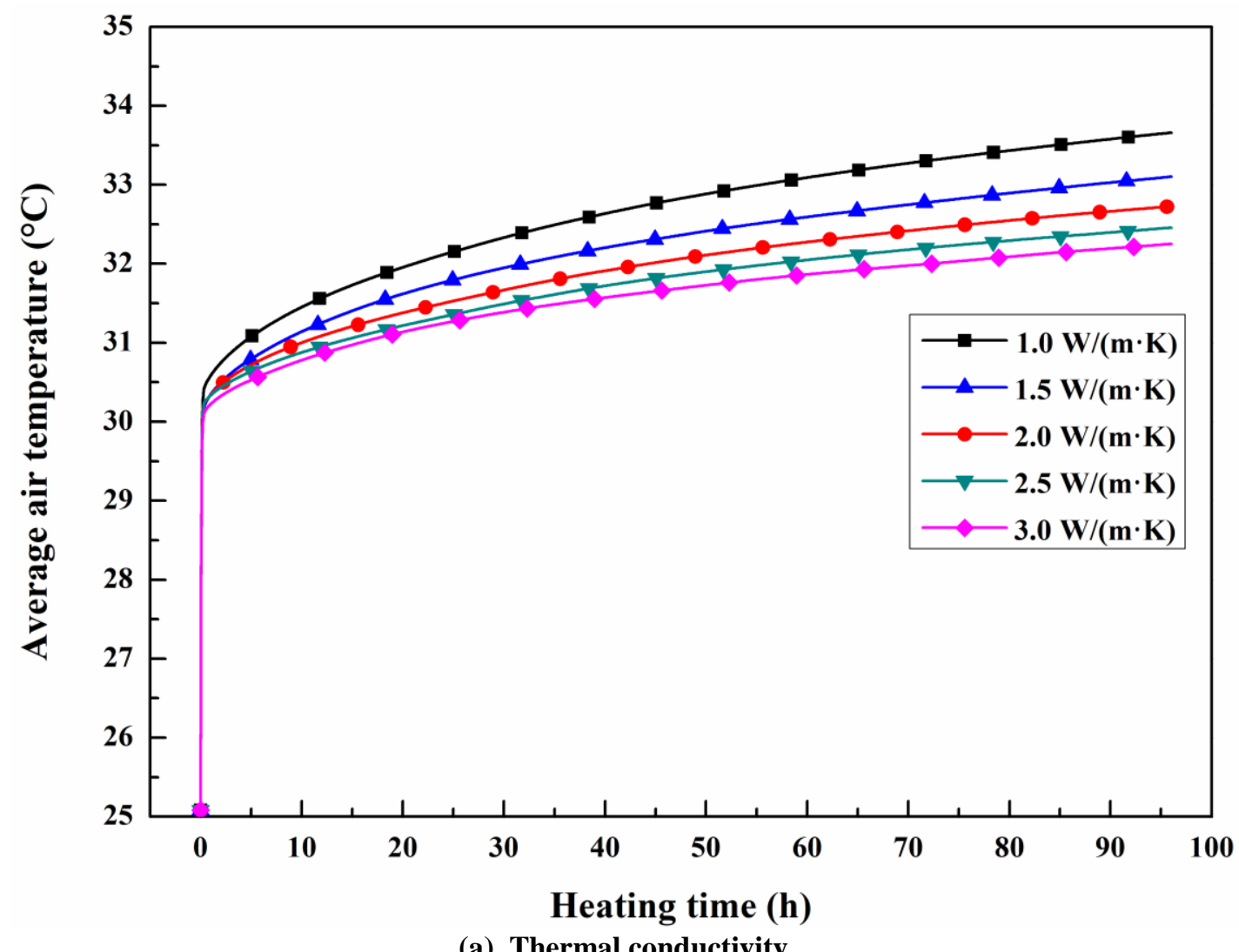

(a) Thermal conductivity 


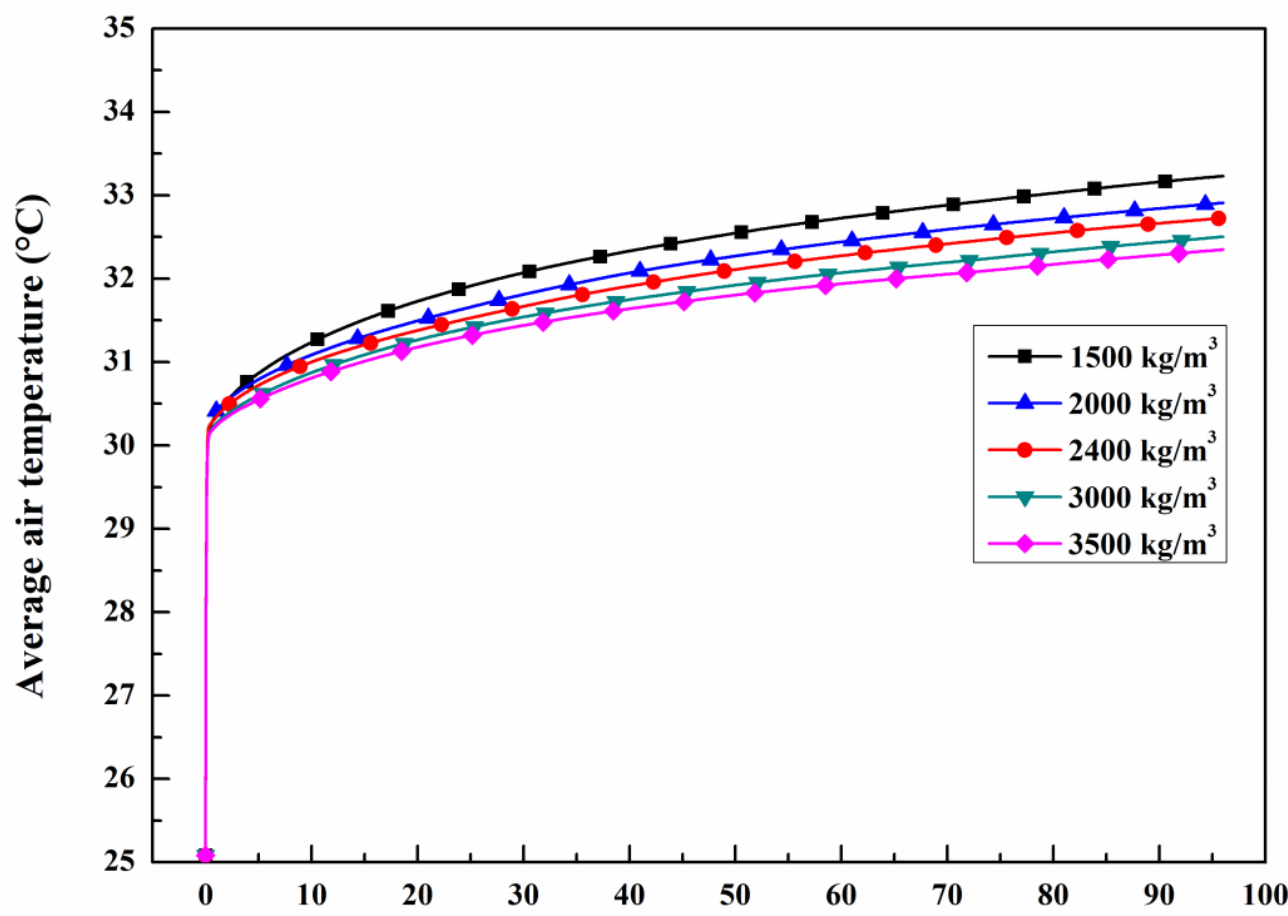

Heating time (h)

(b) Density

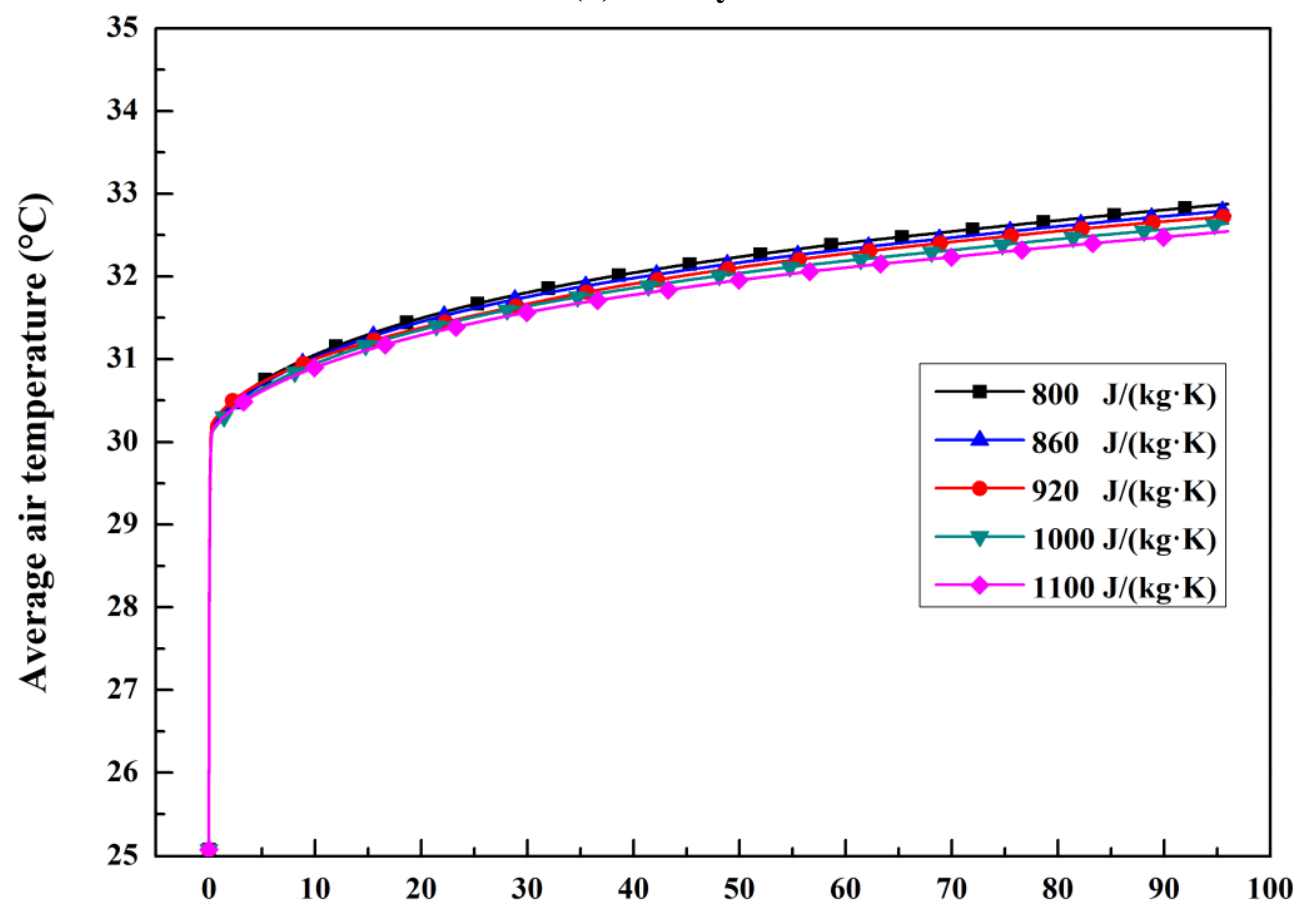

Heating time (h)

(c) Specific heat capacity

Fig. 10. Average air temperature varies with time at different thermal properties of rock.

Fig. 10 (a) shows the average air temperature varies with time at five different thermal conductivity of the rock, i.e. $\lambda=1,1.5,2,2.5$ and $3 \mathrm{~W} /(\mathrm{m} \cdot \mathrm{K})$. It can be found that the CE temperature has approximately equal values of $30.1 \sim 30.4{ }^{\circ} \mathrm{C}$ under different thermal conductivity of the rock. During the ATSI stage, the air temperature rise rate gradually decreases with the thermal conductivity increases.

Fig. 10 (b) shows the average air temperature varies with time at five different density of the rock, i.e. $\rho=1500,2000,2400,3000$ and $3500 \mathrm{~kg} / \mathrm{m}^{3}$. The predicted result indicates that the $\mathrm{CE}$ 
temperature values are equal to $31.1^{\circ} \mathrm{C}$ with the difference less than $0.1{ }^{\circ} \mathrm{C}$ under different density. As the density increases, the air temperature rise rate gradually decreases during the ATSI stage.

Fig. 10 (c) shows the average air temperature varies with time at five different specific heat capacity of the rock, i.e. $C_{\mathrm{p}}=800,860,920,1000,1100 \mathrm{~J} /(\mathrm{kg} \cdot \mathrm{K})$. It can be found that under different specific heat capacity, the $\mathrm{CE}$ temperature is approximately equal to $31.1{ }^{\circ} \mathrm{C}$, and the difference is also less than $0.1^{\circ} \mathrm{C}$. Similarly, the air temperature rise rate gradually decreases with the specific heat capacity increases during the ATSI stage.

It can be found from Fig. 10 that, under the joint action of heat source and ventilation, the heat transfer process between the wall and air in the MRC will quickly reach the state of dynamic equilibrium within less than $0.5 \mathrm{~h}$. Thereafter, the heat transfer process will be in the ATSI stage, and the air temperature rise rate will gradually become slower over time. It can also be concluded that under different thermal properties of the rock, the CE temperature is approximately equal, which indicates that the CE temperature in MRC is independent of the thermal properties of the rock. Namely, the value of $B$ in Eq. (1) does not depend on the thermal conductivity, specific heat capacity, and density of the rock. Meanwhile, it can be concluded that during ATSI stage, as the value of the thermal conductivity, specific heat capacity, and density of the rock increases, the air temperature rise rate gradually decreases, but it is not a linear decreasing relationship. In addition, it can be found that for different thermal properties of the rock, the air temperature in the MRC does not exceed $33.7^{\circ} \mathrm{C}$ in $96 \mathrm{~h}$, which indicates that for a MRC built in common rock, when the initial rock temperature is less than $26.3{ }^{\circ} \mathrm{C}$ and the ventilation volume is $0.3 \mathrm{~m}^{3} / \mathrm{min}$ per person, the air temperature in the MRC will be less than $35^{\circ} \mathrm{C}$ in $96 \mathrm{~h}$, without taking other cool measures.

It can be concluded from the data of Fig. 10 that the air temperature has a nearly linear relationship with $\sqrt{\tau}$ under different properties of the rock, but as the value of $\lambda, \rho$ and $C_{\mathrm{p}}$ increase, the gradient will decrease. This indicates that an MRC built in sandstone rock is more conductive to air temperature control than that built in the coal seam.

\subsubsection{Effect of ventilation parameters}

To investigate the effect of air ventilation volume for MRC, six cases with different ventilation volume are conducted in this section, i.e. $V=300,450,600,900,1200$ and $1500 \mathrm{~m}^{3} / \mathrm{h}$. The other parameters, $\lambda=2 \mathrm{~W} /(\mathrm{m} \cdot \mathrm{K}), \rho=2400 \mathrm{~kg} / \mathrm{m}^{3}, C_{\mathrm{p}}=920 \mathrm{~J} /(\mathrm{kg} \cdot \mathrm{K}), A_{\mathrm{w}}=304 \mathrm{~m}^{2}, Q=6000 \mathrm{~W}$ are keep the same.

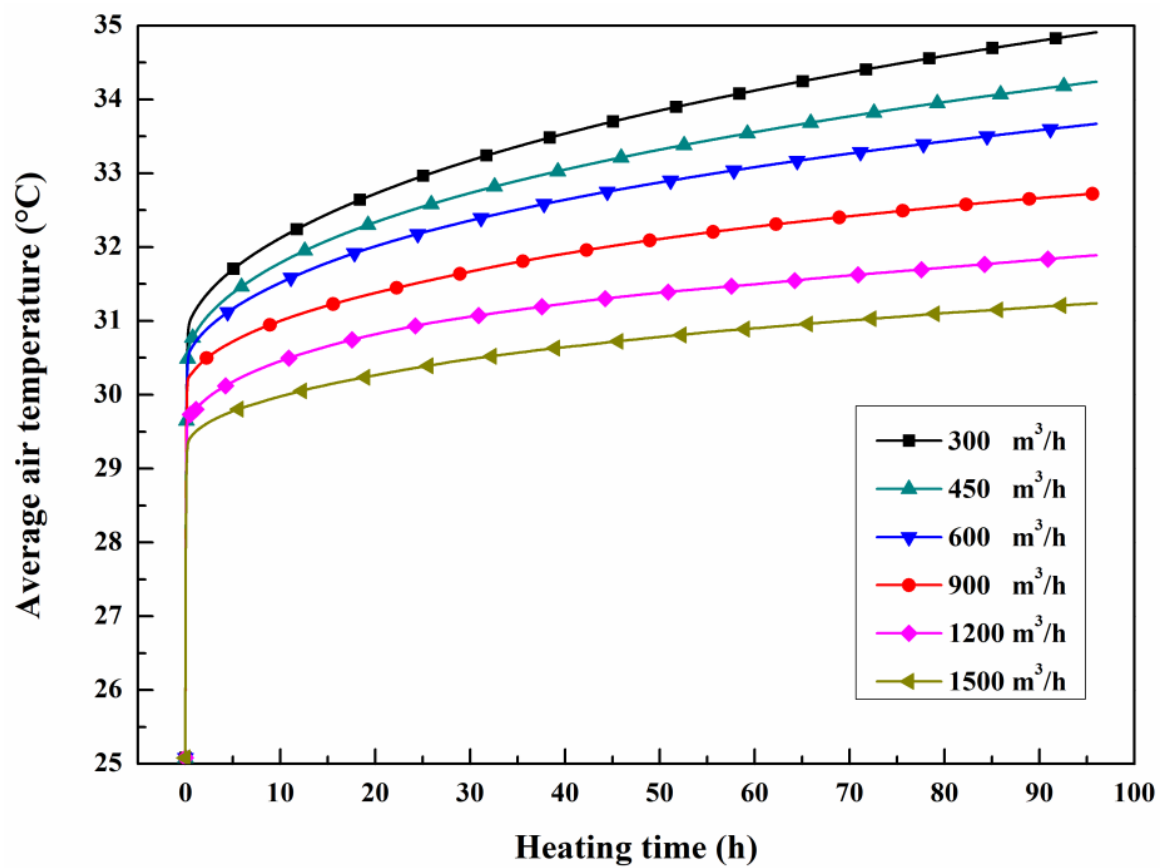

Fig. 11. Average air temperature profiles with heating time 
Fig. 11 shows the average air temperature in MRC varies with time within $96 \mathrm{~h}$ at different air ventilation volume. It can be found that under different ventilation volume, the heat transfer process between the wall and air in MRC also quickly reaches the dynamic equilibrium state within less than $0.5 \mathrm{~h}$. The CE temperature decreases with the ventilation volume increases. During the ATSI stage, as the ventilation volume increases, the gradient of the air temperature increase becomes slower. When the ventilation volume is more than $300 \mathrm{~m}^{3} / \mathrm{h}$, the air temperature in the MRC will not exceed $35{ }^{\circ} \mathrm{C}$ within $96 \mathrm{~h}$, but the air temperature will exceed $32{ }^{\circ} \mathrm{C}$ for a long time at the range of $300 \sim 900 \mathrm{~m}^{3} / \mathrm{h}$, the thermal comfort is poor. When the ventilation is more than $1200 \mathrm{~m}^{3} / \mathrm{h}$, the air temperature will not exceed $32{ }^{\circ} \mathrm{C}$ within $96 \mathrm{~h}$, which result in a good thermal comfort in the MRC.

At $\tau=1 \mathrm{~h}$, the air temperature in the MRC decreases with the ventilation volume increases, and it can be seen that the average air temperature decreases with the increase of the ventilation volume. It can be concluded from the data of Fig. 11 that, the air temperature also shows a nearly linear growth with $\sqrt{\tau}$ when $\tau \geq 1 \mathrm{~h}$ under different ventilation volume rate. The gradient becomes small as the ventilation volume rate increases.

\subsubsection{Effect of heat generation rate in MRC}

To investigate the effect of heat generation rate in the MRC, in this section, a series of cases are conducted for five different heat generation rate: 5000, 6000, 7000, 8000 and $9000 \mathrm{~W}$, while keeping all other parameters unchanged $\left(\lambda=2 \mathrm{~W} /(\mathrm{m} \cdot \mathrm{K}), \rho=2400 \mathrm{~kg} / \mathrm{m}^{3}, C_{\mathrm{p}}=920 \mathrm{~J} /(\mathrm{kg} \cdot \mathrm{K})\right.$, $\left.A_{\mathrm{w}}=304 \mathrm{~m}^{2}, V=900 \mathrm{~m}^{3} / \mathrm{h}\right)$.

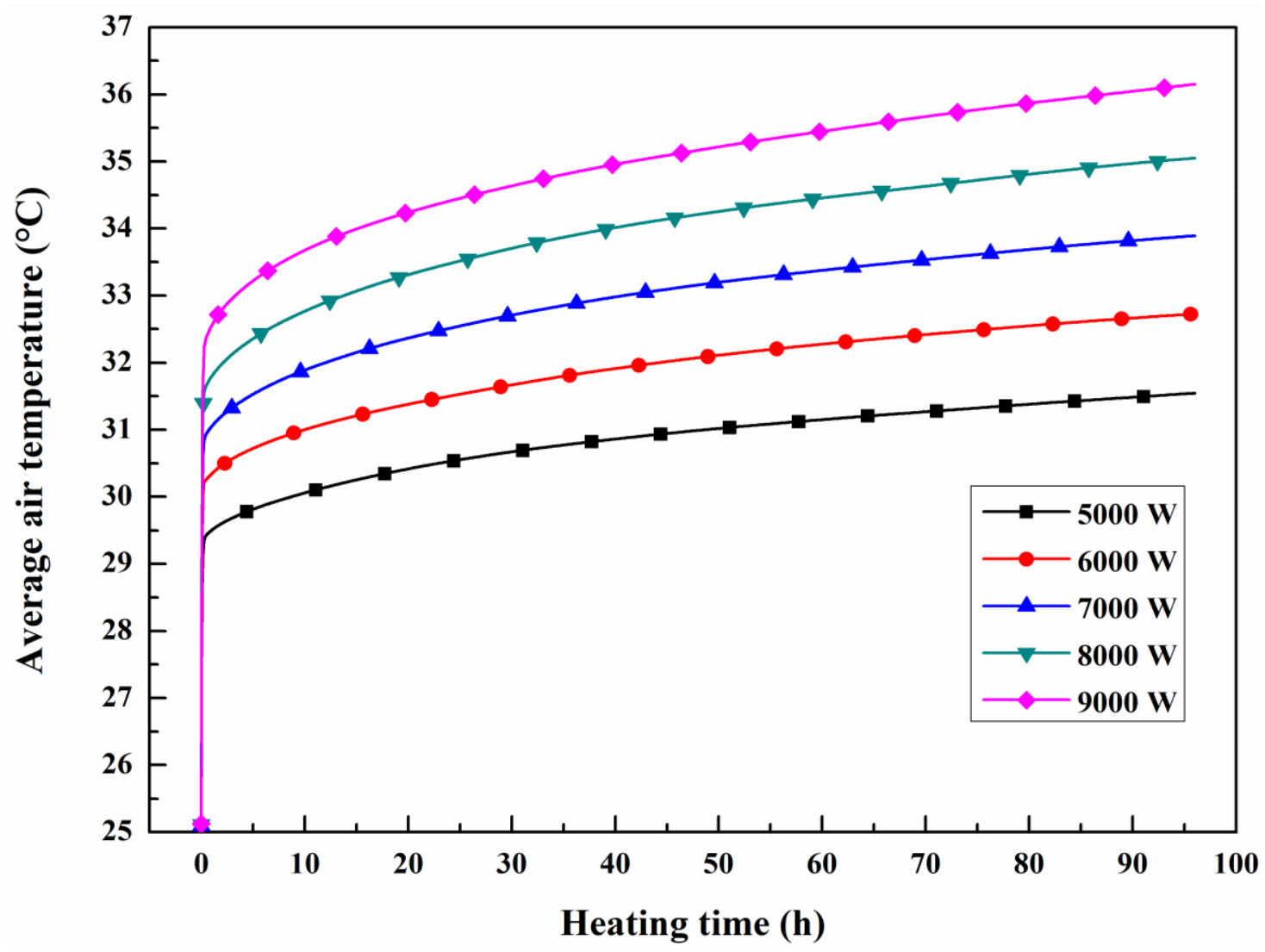

Fig. 12. Average air temperature profiles with time

Fig. 12 shows the average air temperature in MRC varies with time within $96 \mathrm{~h}$ at different heat generation rate. From Fig. 12, the heat transfer process between the wall and air also quickly reaches the state of dynamic equilibrium within less than $0.5 \mathrm{~h}$. It is noted that the larger the heat generation rate in MRC, the higher the CE temperature. During the ATSI stage, the rising rate of the air temperature increases with increasing of $Q$. When $Q=9000 \mathrm{~W}$, the CE temperature is over $32{ }^{\circ} \mathrm{C}$, and the average air temperature will exceed $35^{\circ} \mathrm{C}$ at $96 \mathrm{~h}$. When $Q$ ranges from 7000 to 
$8000 \mathrm{~W}$, the air temperature at $96 \mathrm{~h}$ is less than $35{ }^{\circ} \mathrm{C}$, but the air temperature will exceed $32{ }^{\circ} \mathrm{C}$ for a long time. When $Q$ is less than or equal to $5000 \mathrm{~W}$, the air temperature at $96 \mathrm{~h}$ is less than $32^{\circ} \mathrm{C}$.

It can be observed, according to the data of Fig. 12, that the air temperature in the MRC also shows a nearly linear growth with $\sqrt{\tau}$ when $\tau \geq 1 \mathrm{~h}$ under different heat generation rate, and the gradient increases with the increase of $Q$.

\subsubsection{Effect of Wall Area of MRC}

To investigate the effect of the wall area of MRC, another three models are built with an internal length of the living room as 14, 16 and $18 \mathrm{~m}$, respectively, the corresponding walls area was 220 , 248 and $276 \mathrm{~m}^{2}$. For the purpose of comparison, this section keeps the other parameters remain unchanged: $\left(\lambda=2 \mathrm{~W} /(\mathrm{m} \cdot \mathrm{K}), \rho=2400 \mathrm{~kg} / \mathrm{m}^{3}, C_{\mathrm{n}}=920 \mathrm{~J} /(\mathrm{kg} \cdot \mathrm{K}), Q=6000 \mathrm{~W}, V=900 \mathrm{~m}^{3} / \mathrm{h}\right)$.

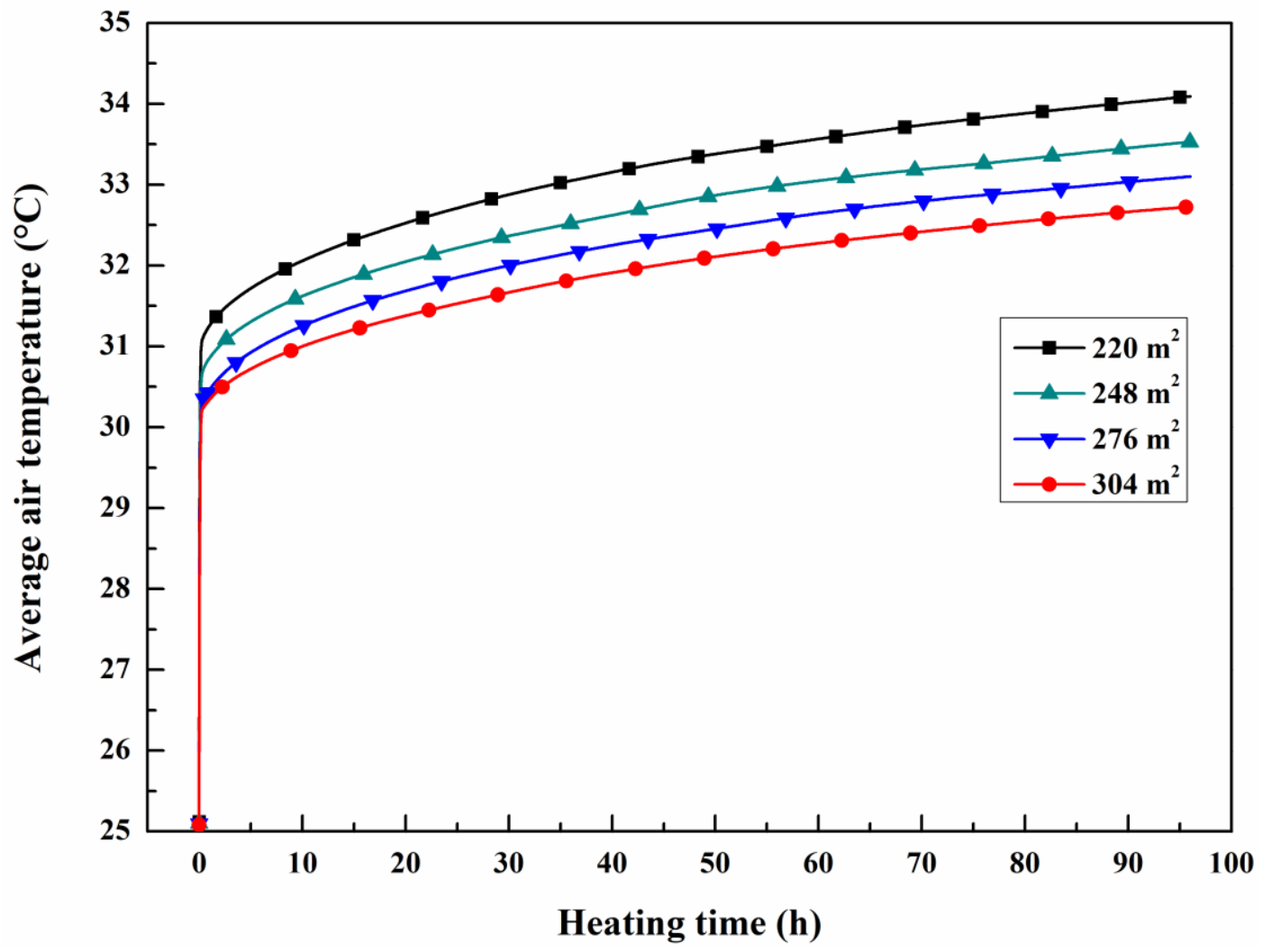

Fig. 13. Average air temperature profiles with time

Fig. 13 shows the average air temperature in MRC varies with time within $96 \mathrm{~h}$ at different wall area of MRC. It can be found that under different wall area of MRC, the heat transfer process between the air and walls also quickly enters a state of dynamic equilibrium within $0.5 \mathrm{~h}$. The CE temperature decreases with the wall area increases. As the wall area increases, the air temperature rising rate decreases at the ATSI stage.

According to the data shown in Fig. 13, it can be obviously observed that the air temperature also shows a nearly linear growth with $\sqrt{\tau}$ when $\tau \geq 1 \mathrm{~h}$ under different wall area. The gradient value increases with the increase of the wall area.

\subsection{Air temperature prediction in MRC}

In order to explore the prediction method of air temperature in a MRC under the condition of the supply air temperature equals to the initial rock temperature, data of air temperature varies with the square root of time for each case is linearly fitted, and values of $K$ and $B$ mentioned in Eq. (1) are obtained. 
Table 2 Values of $\alpha, K$ and $B$ for different conditions

\begin{tabular}{|c|c|c|c|c|c|c|c|c|c|}
\hline$A_{\mathrm{w}}$ & $V$ & $Q$ & $\lambda$ & $\rho$ & $C_{\mathrm{p}}$ & $\alpha$ & \multirow{2}{*}{$K$} & \multirow{2}{*}{$B$} & \multirow{2}{*}{$R^{2}$} \\
\hline $\mathrm{m}^{2}$ & $\mathrm{~m}^{3} / \mathrm{h}$ & W & $\mathrm{W} /(\mathrm{m} \cdot \mathrm{K})$ & $\mathrm{kg} / \mathrm{m}^{3}$ & $\mathrm{~J} /(\mathrm{kg} \cdot \mathrm{K})$ & $\mathrm{W} /\left(\mathrm{m}^{2} \cdot \mathrm{K}\right)$ & & & \\
\hline 304 & 900 & 6000 & 1 & 2400 & 920 & 4.88 & 0.3397 & 5.42 & 0.9945 \\
\hline 304 & 900 & 6000 & 1.5 & 2400 & 920 & 4.92 & 0.2909 & 5.289 & 0.992 \\
\hline 304 & 900 & 6000 & 2 & 2400 & 920 & 4.92 & 0.2625 & 5.203 & 0.9956 \\
\hline 304 & 900 & 6000 & 2.5 & 2400 & 920 & 4.94 & 0.2418 & 5.144 & 0.9961 \\
\hline 304 & 900 & 6000 & 3 & 2400 & 920 & 4.94 & 0.2212 & 5.124 & 0.9937 \\
\hline 304 & 900 & 6000 & 2 & 2400 & 800 & 4.92 & 0.2784 & 5.218 & 0.9923 \\
\hline 304 & 900 & 6000 & 2 & 2400 & 860 & 4.93 & 0.273 & 5.188 & 0.9934 \\
\hline 304 & 900 & 6000 & 2 & 2400 & 1000 & 4.95 & 0.2617 & 5.162 & 0.9923 \\
\hline 304 & 900 & 6000 & 2 & 2400 & 1100 & 4.93 & 0.2509 & 5.142 & 0.9941 \\
\hline 304 & 900 & 6000 & 2 & 1500 & 920 & 4.9 & 0.3055 & 5.314 & 0.9905 \\
\hline 304 & 900 & 6000 & 2 & 2000 & 920 & 4.91 & 0.2797 & 5.241 & 0.995 \\
\hline 304 & 900 & 6000 & 2 & 3000 & 920 & 4.94 & 0.2455 & 5.133 & 0.9941 \\
\hline 304 & 900 & 6000 & 2 & 3500 & 920 & 4.96 & 0.2261 & 5.112 & 0.9938 \\
\hline 304 & 300 & 6000 & 2 & 2400 & 920 & 5.48 & 0.4238 & 5.815 & 0.9986 \\
\hline 304 & 450 & 6000 & 2 & 2400 & 920 & 5.29 & 0.3755 & 5.627 & 0.9971 \\
\hline 304 & 600 & 6000 & 2 & 2400 & 920 & 5.15 & 0.3281 & 5.517 & 0.9966 \\
\hline 304 & 1200 & 6000 & 2 & 2400 & 920 & 5.01 & 0.2263 & 4.736 & 0.9974 \\
\hline 304 & 1500 & 6000 & 2 & 2400 & 920 & 5.21 & 0.1925 & 4.394 & 0.9958 \\
\hline 304 & 900 & 5000 & 2 & 2400 & 920 & 5.1 & 0.2252 & 4.387 & 0.9938 \\
\hline 304 & 900 & 7000 & 2 & 2400 & 920 & 4.96 & 0.3085 & 5.956 & 0.9924 \\
\hline 304 & 900 & 8000 & 2 & 2400 & 920 & 5.1 & 0.3501 & 6.71 & 0.992 \\
\hline 304 & 900 & 9000 & 2 & 2400 & 920 & 5.39 & 0.3953 & 7.372 & 0.9935 \\
\hline 220 & 900 & 6000 & 2 & 2400 & 920 & 5.63 & 0.3149 & 6.085 & 0.9947 \\
\hline 248 & 900 & 6000 & 2 & 2400 & 920 & 5.38 & 0.2959 & 5.731 & 0.9949 \\
\hline 276 & 900 & 6000 & 2 & 2400 & 920 & 5.27 & 0.2778 & 5.362 & 0.9932 \\
\hline
\end{tabular}

Table 2 illustrates values of $\alpha, K$ and $B$ for different cases. It can be found that air temperature in

MRC has a good linear relationship with the square root of time with $R^{2}>0.99$ for each case. Value of $B$ is approximately equal with the value ranging from $5.1 \sim 5.4^{\circ} \mathrm{C}$ under different rock parameters. Therefore, $B$ is not a function of thermal conductivity, specific heat capacity and density of the rock. Thus, Eq. (3) can be expressed as

$$
B=F(V, Q, S, \alpha)
$$

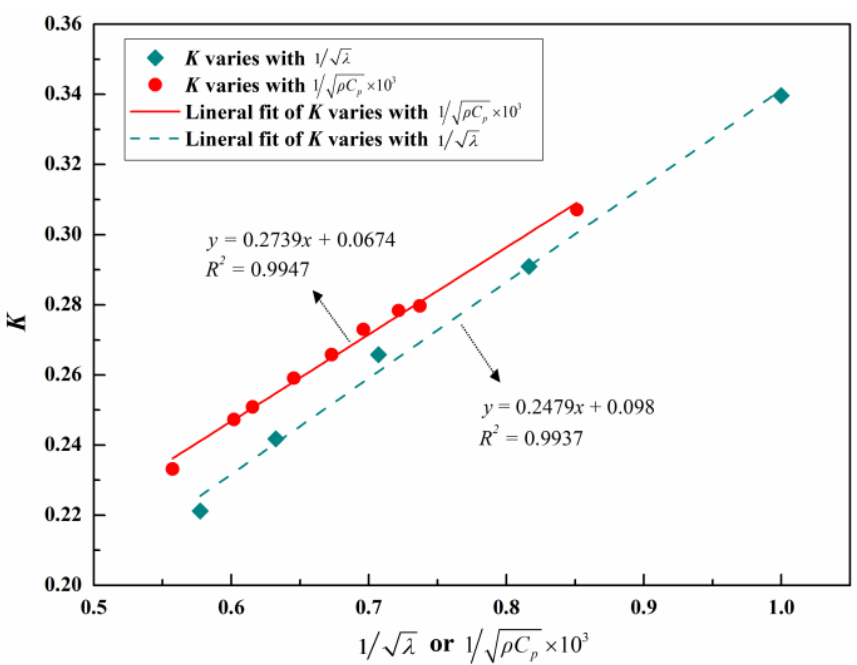

Fig. $14 K$ varies with $1 / \sqrt{\lambda}$ and $1 / \sqrt{\rho \cdot C_{\mathrm{P}}} \times 10^{3}$. 
Fig. 14 plots $K$ varies with $1 / \sqrt{\lambda}$ (both $\rho$ and $C_{\mathrm{p}}$ are kept the same) and $1 / \sqrt{\rho \cdot C_{\mathrm{P}}} \times 10^{3}$ ( $\lambda$ is kept the same), respectively, as well as the corresponding fitting line. It can be found that $K$ has a linear relationship with $1 / \sqrt{\lambda}$ and $1 / \sqrt{\rho \cdot C_{\mathrm{P}}} \times 10^{3}$. The fitting formulas are, $y=0.2739 x+0.0674\left(R^{2}=0.9947\right)$ and $y=0.2479 x+0.098\left(R^{2}=0.9937\right)$, respectively. Therefore, Eq. (2) can be further expressed as follow:

$$
K=f\left(V, Q, A_{\mathrm{w}}, \alpha\right) \cdot f\left(\lambda, \rho, C_{\mathrm{P}}\right)=f\left(V, Q, A_{\mathrm{w}}, \alpha\right) \cdot\left(\frac{1}{\sqrt{\lambda}}+m\right) \cdot\left(\frac{1}{\sqrt{\rho \cdot C_{\mathrm{P}}}}+n\right)
$$

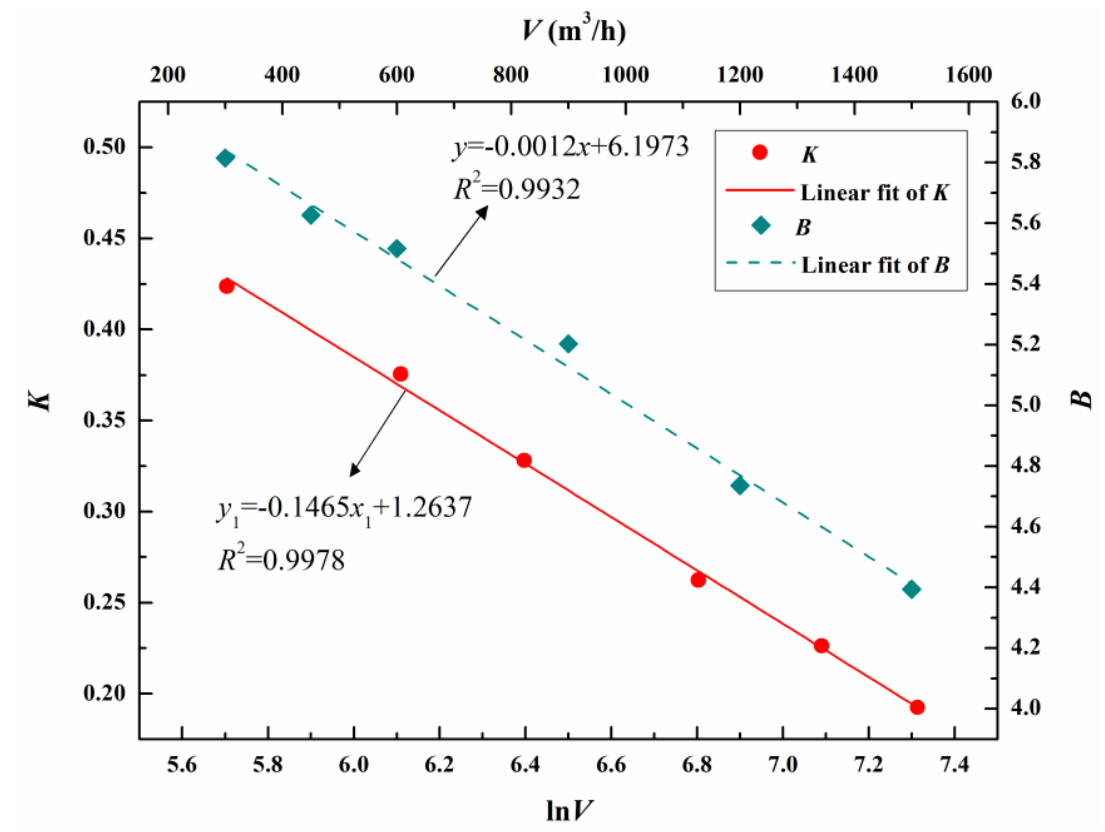

Fig. $16 K$ varies with $\ln V$ and $B$ varies with $V$

Fig.16 plots the $K$ value varies with $\ln V$ and $B$ varies with $V$. It can be found that $K$ decreases linearly with the increase of $\ln V$, the fitting relationship is $y=-0.1465 x+1.2637, R^{2}=0.9978$. Therefore, Eq. (2) can be expressed as

$$
K=f\left(V, Q, A_{\mathrm{w}}, \alpha\right) \cdot f\left(\lambda, \rho, C_{\mathrm{P}}\right) \propto 1 / \ln V
$$

It can be also found from Fig. 16 that $B$ decreases linearly with increasing $V$, the fitting relationship is $y=-0.0012 x+6.1973, R^{2}=0.9932$. Therefore, Eq. (3) can be expressed as

$$
B=F(V, Q, S, \alpha) \propto 1 / V
$$

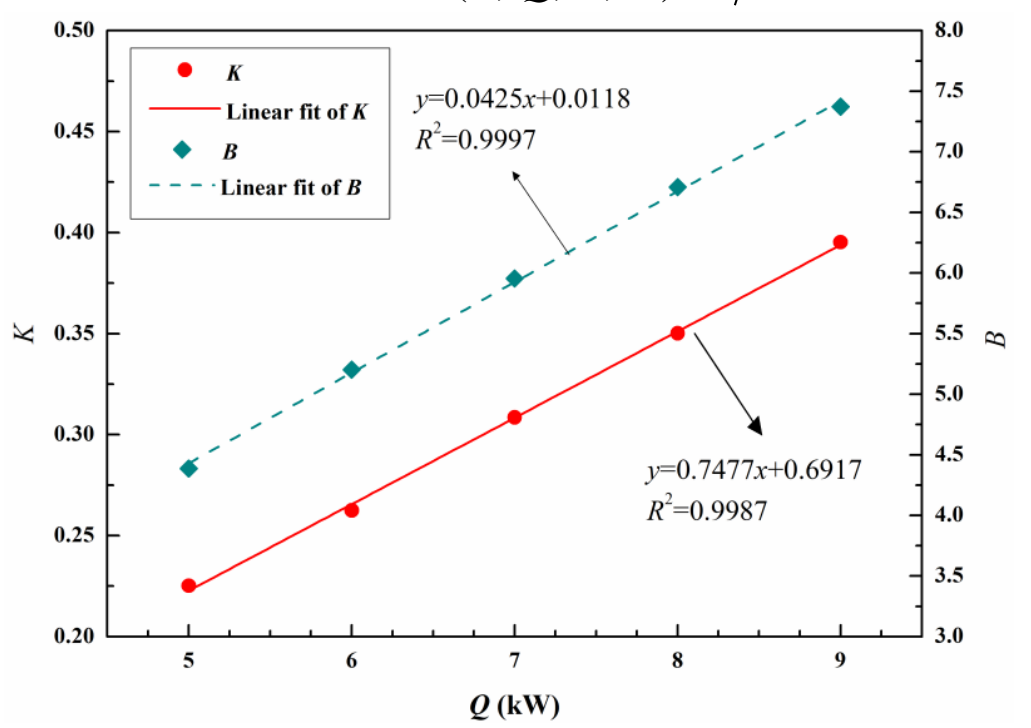

Fig. $17 K$ and $B$ varies with heat generation rate in MRC 
Fig. 17 plots the value of $K$ and $B$ varies with heat generation rate in MRC. It can be found that both $K$ and $B$ decrease linearly with the increase of heat rate in MRC. Among them, the fitting relationship of $K$ varies with $Q$ is $y=0.0425 x+0.0118$ following with $R^{2}=0.9997$, and the fitting relationship of $B$ varies with $Q$ is $y=0.7477 x+0.6917$ following with $R^{2}=0.9987$. Therefore, Eq. (2) and Eq. (3) can be expressed as

$$
\begin{aligned}
K= & f\left(V, Q, A_{\mathrm{w}}, \alpha\right) \cdot f\left(\lambda, \rho, C_{\mathrm{P}}\right) \propto Q \\
& B=F(V, Q, S, \alpha) \propto Q
\end{aligned}
$$

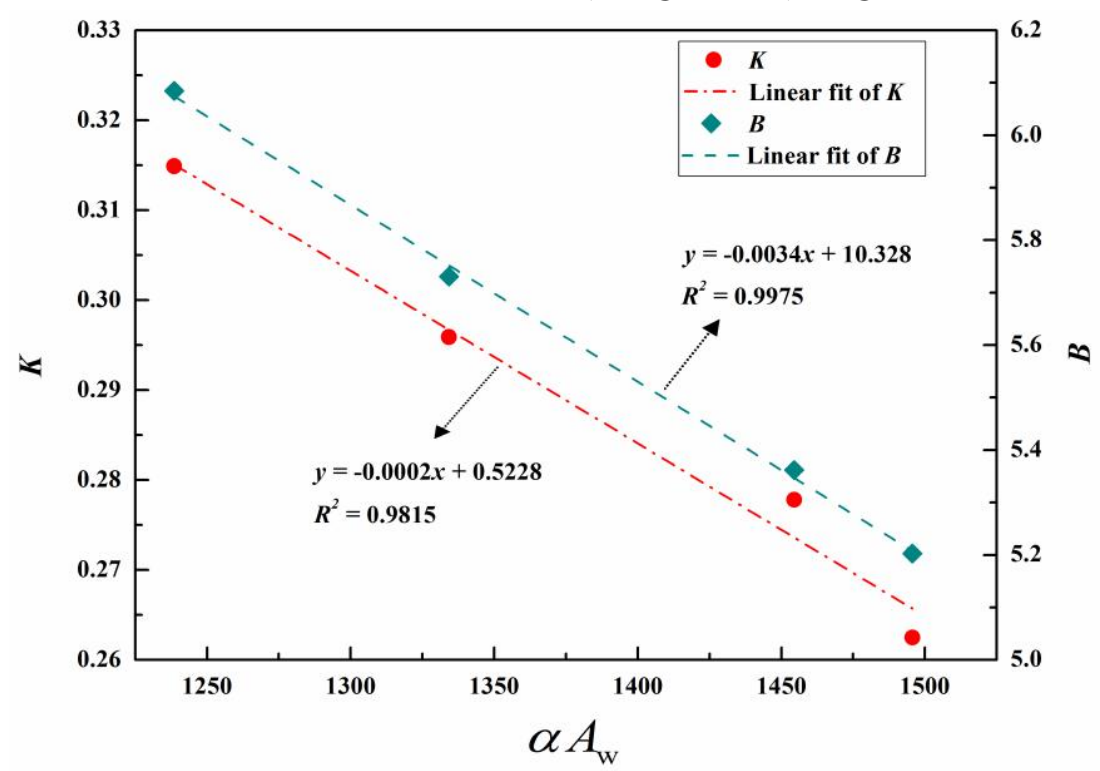

Fig. 18. $K$ and $B$ varies with $\alpha A_{\mathrm{w}}$ in MRC

Fig. 18 shows that both $K$ and $B$ decreases linearly with increasing $\alpha A_{\mathrm{w}}$ according to data of Table 2. It can be found that Both $K$ and $B$ decrease linearly with $\alpha A_{\mathrm{w}}$. Among them, the fitting relationship of $K$ varies with $\alpha A_{\mathrm{w}}$ is $y=-0.0034 x+10.328$ following with $R^{2}=0.9975$, and the fitting relationship of $B$ varies with $\alpha A_{\mathrm{w}}$ is $y=-0.0002 x+0.5228$ following with $R^{2}=0.9815$. Therefore, Eq. (2) and Eq. (3) can be expressed as

$$
\begin{gathered}
K=f\left(V, Q, A_{\mathrm{w}}, \alpha\right) \cdot f\left(\lambda, \rho, C_{\mathrm{P}}\right) \propto 1 /\left(\alpha A_{\mathrm{w}}\right) \\
B=F(V, Q, S, \alpha) \propto 1 /\left(\alpha A_{\mathrm{w}}\right)
\end{gathered}
$$

The above analysis indicted that the air temperature in an MRC is proportional to the heat generation rate in the MRC, but it is inversely proportional to the thermal conductivity, density and specific heat capacity of the rock, as well as the heat generation rate, the ventilation volume rate and the area of the MRC walls.

According to Eqs. (5), (7), (8) and (10), Eq. (2) can be defined as following

$$
K=\frac{Q+a}{b \alpha A_{\mathrm{w}}+c \ln \left(\rho_{\mathrm{a}} V C_{\mathrm{a}}\right)+d}\left(\frac{1}{\sqrt{\lambda}}+m\right)\left(\frac{1}{\sqrt{\rho C_{\mathrm{p}}}} \times 10^{3}+n\right)
$$

Taking the corresponding data in Table 2 to Eq. (12), it can be solved by regression analysis that $a=-725.5, b=13.05, c=9870, d=-66871.4, m=0.32, n=0.4$ with $\mathrm{R}^{2}>0.99$. Therefore, as a proper expression, Eq. (2) can be expressed as

$$
K=\frac{Q-725.5}{13.05 \alpha A_{\mathrm{w}}+9870 \ln \left(\rho_{\mathrm{a}} V C_{\mathrm{a}}\right)-66871.4}\left(\frac{1}{\sqrt{\lambda}}+0.32\right)\left(\frac{1}{\sqrt{\rho C_{\mathrm{p}}}} \times 10^{3}+0.4\right)
$$

According to Eqs. (4), (6), (9) and (11), Eq. (3) can be defined as following

$$
B=\frac{k Q}{i V+j \alpha A_{\mathrm{w}}+l}
$$


Taking the corresponding data in Table 2 to Eq. (14), it can be solved by regression analysis that $i=0.93, j=1.62, k=0.776, l=25.82$ with $\mathrm{R}^{2}>0.99$. Therefore, as a proper expression, Eq. (3) can be written as

$$
B=\frac{0.776 Q}{0.93 V+1.62 \alpha A_{\mathrm{w}}+25.82}
$$

According to Eq. (1), (13) and (15), when the air inlet temperature is equal to the initial rock temperature, the average air temperature in the MRC at the stage of ATSI can be calculated as

$$
T_{\mathrm{a}}(\tau)=\frac{(Q-726) \sqrt{\tau}}{13 \alpha A_{\mathrm{w}}+9870 \ln \left(\rho_{\mathrm{a}} V C_{\mathrm{a}}\right)-66871}\left(\frac{1}{\sqrt{\lambda}}+0.32\right)\left(\frac{1}{\sqrt{\rho C_{\mathrm{p}}}} \times 10^{3}+0.4\right)+\frac{0.78 Q}{0.93 V+1.62 \alpha A_{\mathrm{w}}+25.82}+T_{0}
$$

It should be emphasized here that the proposed analytical method of Eq. (16) is only applicable to the ventilation MRC where the supply air temperature of the inlets is equal to the initial rock temperature, with the time limited in the range of $\tau \leq 96 \mathrm{~h}$. The application of the method will help to determine whether additional cooling measures are needed for a ventilated MRC, and to achieve energy-saving temperature control by enlarging the area of the MRC or increasing the ventilation volume.

\section{Conclusions}

The current study mainly concentrates on the thermal performance of MRC under ventilation to control the air temperature of MRC in no-electric-power and energy-saving way. A series of numerical studies are conducted to investigate the influences of control factors such as the thermal conductivity, density and specific heat capacity of the rock, the ventilation volume, the heat generation rate, as well as the area of the MRC walls. Based on the results of the numerical studies, the following specific conclusions may be made:

(1) During the 96-hours service time, under the condition of ventilation, the coupled heat transfer process between air and wall will reach a relative dynamic balanced state at less than $0.5 \mathrm{~h}$, and the air temperature at this moment is not affected by the thermal properties of the rock, whereas the air temperature is related to the heat generation rate, the ventilation volume and the area of MRC walls. After that, the air temperature increases linearly with the square root of time.

(2) For a common MRC built in sandstone seam, when the initial rock temperature is less than $27{ }^{\circ} \mathrm{C}$ and the air-supply volume is $0.3 \mathrm{~m}^{3} / \mathrm{min}$ per person with the inlet temperature same as the initial rock temperature, the temperature in MRC will not exceed $35{ }^{\circ} \mathrm{C}$ in $96 \mathrm{~h}$.

(3) Under the ventilation, the rate of the air temperature rise is linearly proportional to the heat generation rate in the MRC, but it is inversely proportional to the thermal conductivity, density and specific heat capacity of the rock, the heat generation rate, the ventilation volume and the area of the MRC walls. Therefore, in order to cool temperature in MRC more energy-efficient, coal MRC is more suitably built in rock rather than in the coal seam. In addition, increasing ventilation volume and the area of the MRC can alleviate the air temperature rise.

(4) An analytical method for predicting the air temperature in MRC under ventilation with inlet air temperature equalling to the initial rock temperature is proposed. The method is will provide theoretical guidance in determining the location (built in rock or coal seam) of coal MRC and appropriately enlarging the MRC area or increasing the air-supply volume for MRC to meet the temperature requirement, rather than taking other cooling measures.

\section{Acknowledgments}

The authors would like to thank the financial support from the National Natural Science Foundation of China (NO: 51678488), the Youth Science and Technology Innovation Team of Sichuan Province of Building Environment and Energy Efficiency (No. 2015TD0015), and the Excellent Doctoral Thesis Cultivation Project of Southwest Jiaotong University (D-YB201703) for the financial support for this study. The Chinese Scholarship Council (CSC) is acknowledged for funding one Chinese student in space life with one-year scholarship. 


\section{References}

[1] N. Wang, Y.X. Ren, T. Zhu, F.X. Meng, Z.G. Wen, et al. Life cycle carbon emission modelling of coal-fired power: Chinese case. Energy 162 (2018): 841-852.

[2] A. Shahsavari, M. Akbari. Potential of solar energy in developing countries for reducing energy-related emissions. Renewable and Sustainable Energy Reviews 90 (2018): 275-291.

[3] A.J.H. Nel, J.C. Vosloo, M.J. Mathews. Financial model for energy efficiency projects in the mining industry. Energy 163 (2018): 546-554.

[4] D.P. Tripathy, C.K. Ala. Identification of safety hazards in Indian underground coal mines, Journal of Sustainable Mining (2018), doi: 10.1016/j.jsm.2018.07.005.

[5] K. Wang, S.G. Jiang, X.P. Ma, Z.Y. Wu, H. Shao, W.Q. Zhang, C.B. Cui. Information fusion of plume control and personnel escape during the emergency rescue of external-caused fire in a coal mine. Process Safety and Environmental Protection 103 (2016): 46-59.

[6] D.L. Charles, E.P. Inoka. Evaluation of criteria for the detection of fires in underground conveyor belt haulage ways. Fire Safety Journal 51 (2012):110-119

[7] K.A. Margolis, C.Y.K. Westerman, K.M. Kowalski-Trakofler. Underground mine refuge chamber expectations training: program development and evaluation. Safety Science 49 (2011): $522-530$.

[8] C. Mejías, D. Jiménez, A. Muñoz, L. Reyes-Bozo. Clinical response of 20 people in a mining refuge: Study and analysis of functional parameters. Safety Science 63 (2014): 204-210.

[9] L. Meng, Y.D. Jiang, Y. Zhao, et al. Probing into design of refuge chamber system in coal mine[J]. Procedia Engineering 26 (2011): 2334-2341.

[10]Z.J. Zhang, Y.P. Yuan, K.Q. Wang, X.K. Gao, X.L. Cao. Experimental investigation on influencing factors of air curtain systems barrier efficiency for mine refuge chamber. Process Safety and Environmental Protection 102 (2016): 534-546.

[11]Z.J. Zhang, R. Day, K.Q. Wang, H.W. Wu, Y.P. Yuan. Thermal performance analysis of an underground closed chamber with human body heat sources under natural convection. Applied Thermal Engineering 145 (2018): 453-463.

[12]X. Xu, S.J. You, X.J. Zheng, H. Zhang, S. Liu. Cooling performance of encapsulated ice plates used for the underground refuge chamber. Applied Thermal Engineering 112 (2017): 259-272.

[13]Z.J. Zhang, Y.P. Yuan, K.Q. Wang. Effects of number and layout of air purification devices in mine refuge chamber. Process Safety and Environmental Protection 105 (2017): 338-347.

[14]Y. Du, W.M. Gai, L.Z. Jin, S. Wang. Thermal comfort model analysis and optimization performance evaluation of a multifunctional ice storage air conditioning system in a confined mine refuge chamber. Energy 141 (2017): 964-974.

[15]E.R. Bauer, J.L. Kohler. Update on refuge alternatives: research, recommendations and underground deployment. Mining Engineering 61 (2009): 51-57.

[16]R.G. Steadman. The assessment of sultriness. Part I: a temperature-humidity index based on human physiology and clothing science. Journal of Applied Meteorology 18 (1979): 861-873.

[17] Y. Du, S. Wang, L.Z. Jin, S. Wang, W.M. Gai. Experimental investigation and theoretical analysis of the human comfort prediction model in a confined living space. Applied Thermal Engineering 141 (2013): 61-69.

[18]Y. Li, Y.P. Yuan, C.F. Li, X. Han, X.S. Zhang. Human responses to high air temperature, relative humidity and carbon dioxide concentration in underground refuge chamber. Building and Environment 131 (2018): 53-62.

[19]Y.P. Yuan, X.K. Gao, H.W. Wu, Z.J. Zhang, X.L. Cao, L.L. Sun, N.Y. Yu. Coupled cooling method and application of latent heat thermal energy storage combined with pre-cooling of envelope: method and model development. Energy 119 (2017): 817-833.

[20]Y.X. Jia, Y.S. Liu, S.F. Sun, H.Y. Li, L.L Jiao. Refrigerating characteristics of ice storage capsule for temperature control of coal mine refuge chamber. Applied Thermal Engineering 75 (2015): 756-762.

[21]S. Wang, L.Z. Jin, Z.L. Han, Y.G. Li, S.N. Ou, N. Gao, Z.L. Huang. Discharging performance of a forced-circulation ice thermal storage system for a permanent refuge chamber in an 
underground mine. Applied Thermal Engineering 110 (2017): 703-709.

[22]J.L. Yang, L.W. Yang, J. Wei, Y.Z. Ma, Z.T. Zhang. Study on open-cycle carbon dioxide refrigerator for movable mine refuge chamber. Applied Thermal Engineering 52 (2013): 304312.

[23]X.K. Gao, Y.P. Yuan, X.L. Cao, H.W. Wu, X.D. Zhao. Coupled cooling method and application of latent heat thermal energy storage combined with pre-cooling of envelope: Sensitivity analysis and optimization. Process Safety and Environmental Protection 107 (2017): 438-453.

[24]X.K. Gao, Y.P. Yuan, X.L. Cao, H.W. Wu, X.D. Zhao. Coupled cooling method and application of latent heat thermal energy storage combined with pre-cooling of envelope: Optimization of pre-cooling with intermittent mode. Sustainable Cities and Society 38 (2018): 370-381.

[25]X.K. Gao, Y.P. Yuan, X.L. Cao, H.W. Wu, X.D. Zhao, et al. Coupled cooling method and application of latent heat thermal energy storage combined with pre-cooling of envelope: Temperature control using phase-change chair. Sustainable Cities and Society 42 (2018): 38-51.

[26]X.K. Gao, Z.J. Zhang, Y.P. Yuan, X.L. Cao, C. Zeng, D. Yan. Coupled cooling method for multiple latent heat thermal storage devices combined with pre-cooling of envelope: Model development and operation optimization. Energy 159 (2018): 508-524.

[27]M. Ouzzane, P. Eslami-Nejad, M. Badache, Z. Aidoun. New correlations for the prediction of the undisturbed ground temperature. Geothermics 53 (2015): 379-384.

[28] M. Badache, P. Eslami-Nejad, M. Ouzzane, Z. Aidoun, L. Lamarche. A new modeling approach for improved ground temperature profile determination. Renewable Energy 85 (2016): 436-444.

[29]F.Q. Huang, J.Y. Zhang, S.M. Xie, A.X. Wang. The Thermal Calculation Method of Underground Engineering [M] China Architecture and Building Press, Beijing 1983 (in Chinese).

[30] Y.M. Xiao, X.C Liu, R.R. Zhang. Calculation of transient heat transfer through the envelope of an underground cavern using Z-transfer coefficient method. Energy and Buildings 48 (2012): 190-198

[31]H. Su, X.B. Liu, L. Ji, J.Y. Mu. A numerical model of a deeply buried air-earth-tunnel heat exchanger. Energy and Buildings 48 (2012): 233-239.

[32]A.P. Sasmito, J.C. Kurnia, E. Birgersson, A.S. Mujumdar. Computational evaluation of thermal management strategies in an underground mine. Applied Thermal Engineering 90 (2015): 1144-1150.

[33]L. Kajtar, J. Nyers, J. Szabo. Dynamic thermal dimensioning of underground spaces. Energy 87 (2015): 361-368.

[34]J. Szabó, L. Kajtár J. Nyers, B. Bokor. A new approach and results of wall and air temperature dynamic analysis in underground spaces. Energy 106 (2016): 520-527.

[35]A. Habibi, R.B. Kramer, A.D.S. Gillies. Investigating the effects of heat changes in an underground mine. Applied Thermal Engineering 90 (2015): 1164-1171.

[36] Y. Zhang, Z. Wan, B. Gu, C.B. Zhou. An experimental investigation of transient heat transfer in surrounding rock mass of high geothermal roadway. Thermal Science 20 (2016): 2149-2158.

[37]A.G. Li, C.Q. Yang, T. Ren. Modeling and parametric studies for convective heat transfer in large, long and rough circular cross-sectional underground tunnels. Energy and Buildings 127 (2016): 259-267.

[38]D.S. Yantek, L. Yan, P.T. Bissert, M.D. Klein. Effects of mine strata thermal behavior and mine initial temperatures on mobile refuge alternative temperature. Mining Engineering 69 (2017): 41-48.

[39]ANSYS Inc. ANSYS FLUENT User's Guide, Release 18.0, 2017.

[40]ANSYS Inc. ANSYS 18.0, ICEM CFD User Manual, 2017.

[41]T. Wu, C.W. Lei. On numerical modelling of conjugate turbulent natural convection and radiation in a differentially heated cavity. International Journal of Heat and Mass Transfer 91 (2015): 454-466. 
[42]D.N. Sørensen, P.V. Nielsen. Quality control of computational fluid dynamics in indoor environments. Indoor Air 13 (2003): 2-17.

[43]E. Bacharoudis, M.G. Vrachopoulos, M.K. Koukou, D. Margaris, A.E. Filios, S.A. Mavrommatis. Study of the natural convection phenomena inside a wall solar chimney with one wall adiabatic and one wall under a heat flux. Applied Thermal Engineering 27 (2007): 2266-2275.

[44] A. Piña-Ortiz, J.F. Hinojosa, V.M. Maytorena. Test of turbulence models for natural convection in an open cubic tilted cavity. International Communications in Heat and Mass Transfer 57 (2014): 264-273.

[45]A. Piña-Ortiz, J.F. Hinojosa, J. P. Xamán, V.M. Maytorena. Test of turbulence models for heat transfer within a ventilated cavity with and without an internal heat source. International Communications in Heat and Mass Transfer 94 (2018): 106-114.

[46]H. Shao, S.G. Jiang, W.Y. Tao, Z.Y. Wu, W.Q. Zhang, K. Wang. Theoretical and numerical simulation of critical gas supply of refuge chamber. International journal of mining science and technology 26 (2016): 389-393.

[47]K. Ahmed, A. Akhondzada, J. Kurnitski, B. Olesen. Occupancy schedules for energy simulation in new prEN16798-1 and ISO/FDIS 17772-1 standards. Sustainable Cities and Society 35 (2017): 134-144.

[48]National Coal Mine Safety Administration (China). Provisional Provisions on Construction and Management of underground coal mine emergency refuge system. 2011. http://www.chinacoalsafety.gov.cn/gk/tzgg/201101/t20110127_201854.shtml 